Brazilian Journal

of Chemical

Engineering

\title{
STUDY OF SOLUBILITY IN SUPERCRITICAL FLUIDS: THERMODYNAMIC CONCEPTS AND MEASUREMENT METHODS - A REVIEW
}

\author{
Hadi Behjati $\operatorname{Rad}^{1}$, Javad Karimi Sabet ${ }^{2 *}$ and Farshad Varaminian ${ }^{1 *}$ \\ ${ }^{1}$ Semnan University, Faculty of Chemical, Petroleum and Gas Engineering, Semnan, Iran. E-mail: fvaraminian@semnan.ac.ir - \\ ORCID: 0000-0002-5188-3611 \\ ${ }^{2}$ Nuclear Science and Technology Research Institute, Material and Nuclear Fuel Research School, Tehran, Iran. \\ E-mail: j_karimi@alum.sharif.edu - ORCID: 0000-0001-9937-7171
}

(Submitted: September 21, 2017 ; Revised: November 8, 2018 ; Accepted: November 22, 2018)

\begin{abstract}
Due to the importance of supercritical fluid technology (SFT) in different industries, it has been the subject of intense research in recent decades. Solubility is a key concept in SFT. In fact, obtaining knowledge about the theoretical concepts of solubility and related experimental measurement methods can be useful in developing and improving the quality of research in this field. This study reviews the fundamental knowledge of solubility in supercritical fluids and investigates the significant topics in this field, including high-pressure phase behavior, experimental measurement methods, modeling, and molecular simulation of solubility.

Keywords: Solubility; Supercritical fluids; High-pressure phase behavior; Experimental measurement methods; Molecular simulation.
\end{abstract}

\section{INTRODUCTION}

In recent years, scientists have extensively focused on supercritical fluid technology (SFT) as a new method for important processes such as reaction, extraction, purification, and production of nanoparticles. This technology has remarkable advantages, such as negligible negative impact on environment, low waste toxicity, better quality, and safety of the final products. Because of the mentioned positive features, supercritical fluids are widely used as an alternative to many organic and environmentally destructive solvents (Beckman, 2004; Jessop and Leitner, 2008).

A supercritical fluid is a fluid at temperature and pressure higher than the critical temperature and pressure, where distinct liquid and vapor phases do not exist. At temperature and pressure below the critical values, liquid and vapor can coexist. In fact, liquid density decreases due to thermal expansion, while the vapor becomes denser as a result of the increase in pressure. The densities of vapor and liquid phases gradually converge and eventually, at the critical point of the fluid, the densities of the two phases will become identical. At this point, both vapor and liquid phases become indistinguishable and there will be no boundary between phases. In fact, a supercritical fluid is an intermediate phase between vapor and liquid phases.

Since supercritical fluids show the properties of both liquid and vapor phases, they can easily dissolve other materials. The solubilizing capability of supercritical fluids highly relies on the pressure value, and at higher pressures a supercritical fluid acts as a better solvent. Near the critical point, supercritical fluids are extremely sensitive to subtle changes in temperature and pressure.

Among various types of supercritical fluids, carbon dioxide is more common and frequently used because it is non-toxic, non-flammable, and nonexplosive and has mild critical properties $\left(\mathrm{T}_{\mathrm{c}}=304.25\right.$ $\mathrm{K}$ and $\mathrm{P}_{\mathrm{c}}=7.38 \mathrm{MPa}$ ). One of the distinguishing properties of supercritical carbon dioxide is its small

\footnotetext{
* Corresponding author: Javad Karimi Sabet and Farshad Varaminian - E-mail: j_karimi@alum.sharif.edu; fvaraminian@semnan.ac.ir
} 
and linear structure which increases its permeability. Nevertheless, supercritical carbon dioxide has some limitations, such as non-polarity and its capacity to form specific solvent-solute interactions. Therefore, to enhance its solubilizing power, it is highly desired to improve its polarity by adding a suitable cosolvent ( $\mathrm{Li}$ et al., 2003; Huang et al., 2004; Karimi-Sabet et al., 2012; Behjati Rad et al., 2019).

In a supercritical fluid system, solubility can be defined as the concentration or mole fraction of a substance in the supercritical phase at equilibrium with the pure fluid. The solubility accelerates the initial stages of an extraction process and reduces the time of the process. In other words, solubility is the ability to extract materials under different temperature and pressure conditions.

Given the significant role of solubility in SFT processes, various methods, including experimental, semiempirical, solubility parameter model, molecular simulation, and equation of state-based methods have been developed for determining and predicting solubility in supercritical fluids. In recent decades, numerous studies have been conducted to investigate the solubility of various materials in supercritical fluids (Aschenbrenner et al., 2007; De Zordi et al., 2012; Karimi-Sabet et al., 2012; Masoodiyeh et al., 2014; Zhu et al., 2015; Bitencourt et al., 2016; Chen et al., 2017; Tamura et al., 2017).

SFT is a relatively new tool to produce important products such as solid particles, powdery composites, and nanostructured materials. In order to produce the mentioned items, it is necessary to utilize various methods and perform different processes such as the rapid expansion of supercritical solution (RESS), the gas anti-solvent (GAS), the supercritical anti-solvent (SAS), and the particles from gas-saturated solution (PGSS) (Knez and Weidner, 2003; Shariati and Peters, 2003; Yeo and Kiran, 2005; Cansell and Aymonier, 2009). For example, this technology is applied in the pharmaceutical industry to produce nanoparticles (Fages et al., 2004; Pathak et al., 2006; Reverchon et al., 2009; Keshavarz et al., 2012; Karimi-Sabet et al., 2012; Akbari et al., 2014; Akbari et al., 2014; Akbari et al., 2015; Masoodiyeh et al., 2015; Fattahi et al., 2016).

SFT can also be used in the food industry for separation and extraction processes (Brunner, 2005; Ruttarattanamongkol et al., 2011), optimization of flat sheet hydrophobic membrane synthesis (Zaherzadeh et al., 2015), and dysprosium ion recovery from aqueous solutions (Karimi-Sabet et al., 2014).

Recent studies on SFT have shown that this technology can be also utilized for chemical and biochemical processes (Ikushima, 1997; Jessop and Leitner, 2008; Santos et al., 2016), synthesis of new materials such as silica aerogel (Błaszczyński et al., 2013; Mahadik et al., 2016), a powerful tool for chiral separations (Speybrouck and Lipka, 2016), optimization of graphene production by exfoliation of graphite (Hadi et al., 2016), dry cleaning (McHardy and Sawan, 1998), high-pressure sterilization (Perrut, 2012), jet cutting (Shen et al., 2011), thin-film deposition for microelectronics (Jianzhong et al., 2009), and separation of value-added products from fermentation broths in the field of biotechnology (Fabre et al., 1999).

Given the significance of solubility in SFT processes, this study reviews the thermodynamic concepts of solubility and related measurement methods. To this end, the first section discusses the phase behavior of fluid mixtures at high-pressure to highlight the complexity of phase behavior under supercritical conditions and its significance in solubility studies. In the second section, experimental methods of solubility measurement are categorized and reviewed briefly. The third section discusses the thermodynamic concepts of high-pressure equilibrium to highlight the importance of equilibrium in modeling solubility. In addition, various methods of modeling solubility in the supercritical fluid are discussed. The final section reviews molecular simulation as a powerful method for predicting solubility.

\section{High-pressure phase behavior of fluid mixtures}

In order to develop and improve supercritical fluid processes, it is essential to consider phase behavior of fluid mixtures under high-pressure conditions. Pressure and temperature have a complicated effect on phase behavior in supercritical fluid systems and may generate different types of phase equilibria in the system. Hence, it is of great importance to have a proper knowledge of the high-pressure phase behavior of fluid mixtures in a phase diagram framework.

Although it is very important to study the phase behavior of pure substances, it only provides limited information about the phase behavior of multicomponent mixtures. In fact, fluid mixtures show different behaviors, which are due to interactions between different molecules and the wide variety of phase transitions that may occur under this condition. However, it is essential to study the high-pressure phase behavior of fluid mixtures, because the first step in designing chemical processes is to obtain information on this type of equilibrium.

The study of phase behavior in binary systems is a starting point for understanding the complexity of phase behavior in multicomponent mixtures. Different types of phase diagrams of mixtures under highpressure conditions are presented by Van Konynenburg and Scott (Van Konynenburg, 1968; Van Konynenburg and Scott, 1980). 


\section{Gibbs phase rule}

The concept of degree of freedom can be used to determine the geometry of a phase diagram. Based on the Gibbs phase rule, the number of thermodynamic degrees of freedom or the number of independent intensive variables can be obtained by Eq. (1):

$\mathrm{F}=\mathrm{N}-\mathrm{P}+2$

where $F$ is the number of thermodynamic degrees of freedom (number of independent intensive variables), $N$ is the number of components in a mixture, and $P$ is the number of coexisting phases in equilibrium.

Temperature, pressure, and composition of all the available phases are intensive variables for a system in an equilibrium state. For example, a binary fluid mixture in a two-phase state has two degrees of freedom. In other words, when the temperature and pressure of the system are known, one can determine the thermodynamic state. For a ternary system in a twophase state, the three variables of temperature, pressure, and the mole fraction of one of the components can be used to determine the thermodynamic state.

In addition to specifying the thermodynamic state of a system, the phase rule also helps to obtain information about the phase diagram geometry. Knowledge about geometry limitations is very useful for determining the number of coexisting phases in different areas of the phase diagram.

\section{Phase behavior of binary mixtures}

Generally, the phase equilibria in binary mixtures can be expressed using five major classes of phase diagrams which can be obtained from the van der Waals equation of state. Based on the phase rule, a binary system can be fully described by a threedimensional phase diagram, such as a $P-T-x$ diagram. In other words, the phase diagrams can be expressed using a two-dimensional projection of three-phase lines and critical mixture curves obtained from threedimensional $P-T-x$ diagrams. This type of phase diagrams has two types of limiting points, including critical points and critical end points. The intersection of three-phase equilibrium lines (LLV equilibrium lines) and critical lines generate a critical endpoint (Van Konynenburg, 1968; Van Konynenburg and Scott, 1980; Streett, 1989; McHugh and Krukonis, 2013). The five classes of van der Waals phase diagrams are shown in Fig. 1.

According to previous studies, a subset of the Class III phase diagram is the most applicable for binary solid-supercritical fluid systems. As shown in Fig. 2 (Streett, 1989; Lucien and Foster, 2000; McHugh and Krukonis, 2013), $\mathrm{C}_{1}$ and $\mathrm{C}_{2}$ are the critical points of components 1 and 2, respectively. The dashed curves represent the locus of critical points in binary mixtures

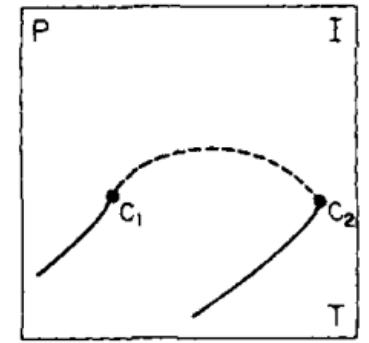

(a)

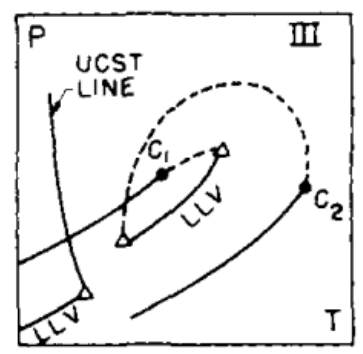

(c)

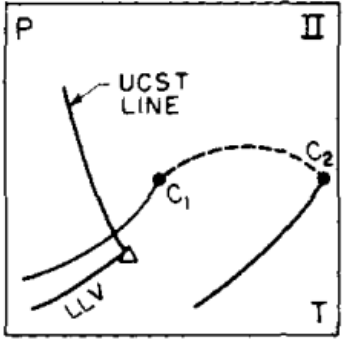

(b)

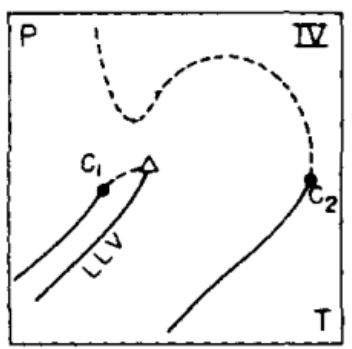

(d)

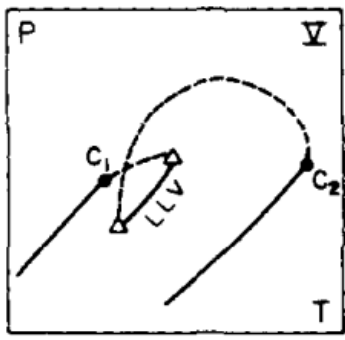

(e)

Figure 1. Phase behavior classification of binary mixtures obtained from the van der Waals equation of state. Points $\mathrm{C}_{1}$ and $\mathrm{C}_{2}$ are the critical points of components 1 and 2, respectively. UCST and LLV imply the upper critical solution temperature and threephase equilibrium between two liquid phases and one vapor phase, respectively. Solid lines represent pure component vapor pressure curves, dashed curves are the critical mixture curve for a binary mixture, and open triangles are the critical endpoints (McHugh and Krukonis, 2013).

while the dashed-dotted curves represent the solidliquid-vapor equilibrium. The intersection of threephase equilibrium lines and critical lines represent the critical end points. These critical end points may occur either at a high-temperature branch of the three-phase curve (UCEP) or a low-temperature branch (LCEP).

The solid-liquid-vapor equilibrium curve of a solid material starts from its normal melting point and ends at the upper critical endpoint. The area between UCEP and LCEP in the phase diagram represents the temperature range in which solid-vapor equilibrium exists. The composition of heavy components in the vapor phase refers to a solid solubility in the 


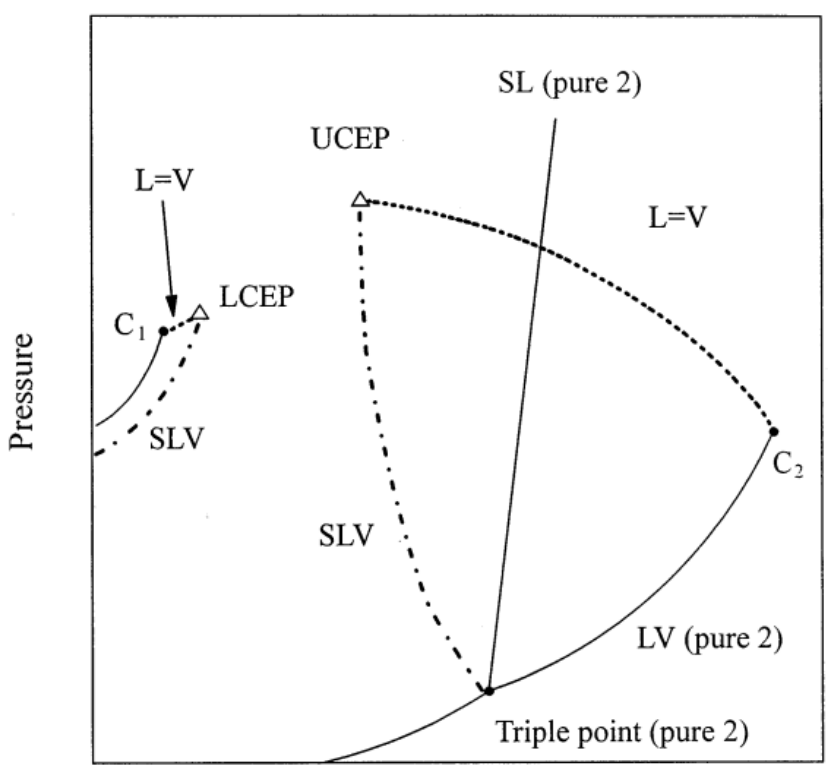

Temperature

Figure 2. Phase diagram for an asymmetric binary system consisting of a solid (second component) in the presence of supercritical carbon dioxide (first component) (Lucien and Foster, 2000).

supercritical fluid. It is worth noting that the largest body of data on solid solubility in supercritical fluids is obtained from this area.

The pure solid melting point, as an important variable for determining solubility, decreases under high-pressure conditions. Lucien and Foster (Lucien and Foster, 2000) studied the solubility of solid mixtures and showed that the phase behavior of a system can be affected by the solid phase melting point under high-pressure conditions and the formation of liquid phase. It is an important item in equilibrium calculations. Under this condition, both the liquidvapor and solid-liquid-vapor equilibrium are possible and the distribution of components in the vapor phase or supercritical fluid phase can be different from our expectations. In other words, the data on the number and type of stable phases in the equilibrium state play a crucial role in the study of the phase equilibrium. In fact, phase stability calculations are a prerequisite for equilibrium calculations.

As mentioned above and as stated by Lucien and Foster (2000), the presence of a supercritical fluid decreases the normal melting point of a pure solid, which significantly affects the composition of the vapor phase and solid solubility. Fig. 3 represents a $P$ - $x$ projection of the phase diagrams previously shown in Fig. 2.

According to Fig. 3, the increase in pressure results in changes in the equilibrium conditions and generates two different regions of phase behavior. When the composition is lower than $x_{L}$, there is a solid-

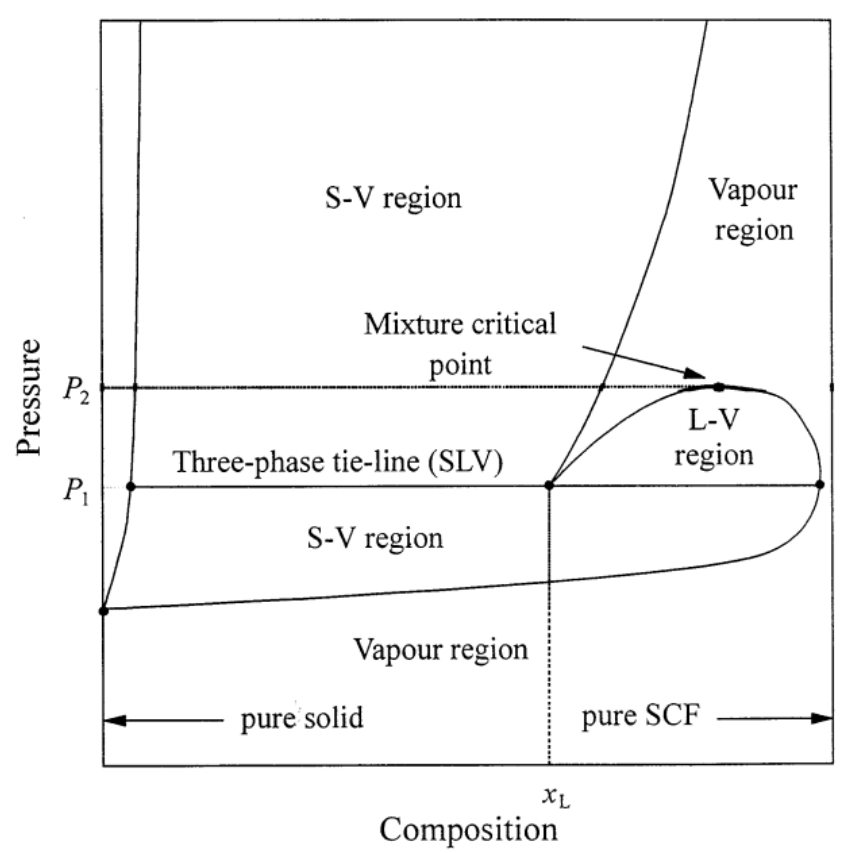

Figure 3. $P-x$ projection of the phase diagram at a temperature which intersects the SLV line (Lucien and Foster, 2000).

vapor equilibrium, and the composition of the vapor phase in this region indicates solid solubility in the supercritical fluid. However, when the composition is higher than $x_{t}$, liquid-vapor equilibrium is established up to the stationary point at pressure $P_{2}$ and the vapor phase composition in this region indicates the liquid solubility in the supercritical fluid (Lucien and Foster, 2000).

\section{Phase behavior of ternary mixtures}

Many theoretical and experimental studies in the field of fluid phase behavior are conducted on binary mixtures, however, a large number of fluid mixtures have more than two components. Hence, the study of the phase behavior of multicomponent mixtures is of great importance.

Regardless of components with very small amounts, multicomponent systems can be modeled as pseudo-ternary systems. Thus, extensive attempts have been made to determine the phase behavior of ternary mixtures of various compounds under highpressure conditions (Kurnik and Reid, 1982; Johnston and Penninger, 1989; Liu and Nagahama, 1996; Freitag et al., 2006; Fu et al., 2007; Chobanov et al., 2010; Deiters and Kraska, 2012; Sadus, 2012; Yang et al., 2012; Rebelatto et al., 2015).

Every ternary system has three subsystems, each having a specific phase behavior similar to one of the phase diagrams of binary systems. In order to study the phase behavior of a ternary system, it is necessary to improve the knowledge about the graphical representation of these subsystems. Consequently, 
upon adding a third component to the binary system, a third dimension will be required to analyze the phase behavior; it can be explained using the Gibbs phase triangle. The corners of the triangle represent the pure components. The mole fractions of a component can be determined through calculating the ratio of the distances from the edges to the height of the triangle (Deiters and Kraska, 2012). Fig. 4 presents an example of this triangle with the hypothetical mole fractions in a ternary system.

Concerning solubility, in order to enhance the solubility of a solid solute, for example in pharmaceutical industries, ternary mixtures are usually produced through adding a cosolvent to the supercritical fluid (Li et al., 2003).

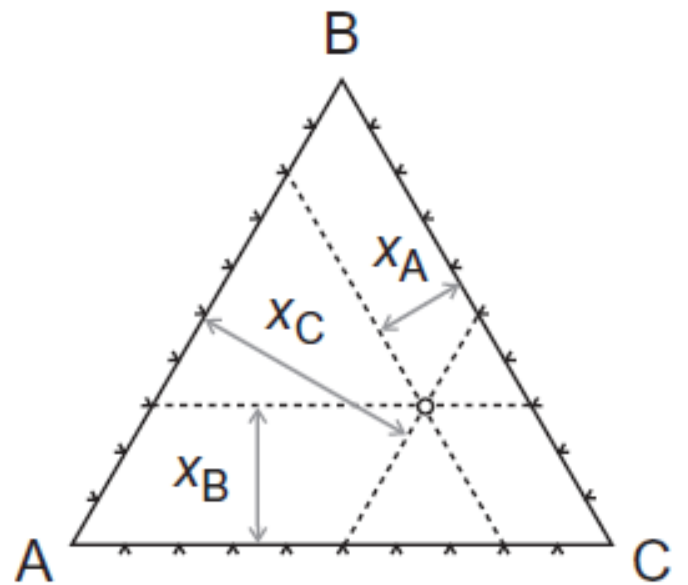

Figure 4. Gibbs phase triangle for a ternary system, the composition of the mixture is $\mathrm{x}_{\mathrm{A}}=0.2, \mathrm{x}_{\mathrm{B}}=0.3$ and $\mathrm{x}_{\mathrm{C}}=0.5$ (Deiters and Kraska, 2012).

\section{Experimental methods of solubility measurement}

The solubility of a material in a supercritical fluid can be determined by measuring its amount in a saturated solution. Generally, solubility is reported as mole fraction or mass fraction.

Several experimental methods have been developed for measuring the solubility and studying high-pressure phase equilibria. Depending on the type of technique applied for measuring the concentration, these methods are divided into two main categories, including analytic and synthetic approaches. In addition to these two main categories of methods, there are transient methods, which can be classified into two types: material flow and heat flow. They can be used to study the high-pressure phase equilibria (Deiters and Kraska, 2012).

Many researchers have conducted comprehensive studies in this field to investigate various types of highpressure phase equilibria (Christov and Dohrn, 2002; Dohrn and Brunner, 1995; Fornari et al., 1990; Dohrn et al., 2010; Fonseca et al., 2011). In addition, Aim and Fermeglia (2002) investigated on solubility and achieved significant results. In the following section, these experimental methods and their main concepts are briefly discussed.

\section{Analytic methods}

When using analytic methods for experimental examinations, the overall composition of the fluid sample is unknown. In these methods, the temperature and pressure are changed until the phase separation occurs. Therefore, the composition of coexisting phases is analyzed using conventional chromatography methods such as gas chromatography (GC), high performance liquid chromatography (HPLC), and thin layer chromatography (TLC). Since many materials have a low level of solubility in supercritical fluids and their UV sensitivity is insignificant, chromatography instruments have a key role in measuring solubility (Yoda et al., 2008; Li et al., 2016).

The selection of analysis methods depends mainly on the type of materials and their solubility in supercritical fluids. For instance, the GC method is not appropriate for temperature-sensitive materials, while the HPLC method is suitable for materials with a very low level of solubility. Concerning the techniques used for classifying phase equilibria, analytic methods are divided into four categories: static method, recirculation method, flow method, and saturation method. Each of these methods is briefly introduced in the following sections.

Analytic-static method

In the analytic-static method, the volume of the equilibrium vessel is fixed and solid or liquid solute will be contacted with a certain volume of the supercritical fluid. In this method, to reach the equilibrium state faster and better, a mixer is used exclusively for liquid solutes in the equilibrium vessel. After achieving the equilibrium state, a small sample of the fluid is collected and its composition is analyzed using chromatography methods.

Although the governing principles of the analyticstatic method are simple, it is necessary to ensure the achievement of the equilibrium state prior to the sampling of the fluid. Hence, enough time is needed for making a proper contact between the solute and solvent. Moreover, sampling is an important step in the analytic-static method and it should be performed carefully. In fact, sampling from the equilibrium vessel must not disturb the equilibrium conditions. As a result, only a small volume of the fluid should be taken for the analysis.

The analytic-static method can be used to study the phase equilibrium of binary, ternary, and multicomponent systems in the supercritical fluid. Gutiérrez et al. (2010) explained the application of this method for modeling high-pressure equilibria in binary systems. 
The analytic-static method is widely used to measure solubility in supercritical fluids, such as the solubility of condensed compounds (Galia et al., 2002), nitrophenol derivatives (Shamsipur et al., 2002), drugs (Hojjati et al., 2007), and many other materials (Park et al., 2009; Hosseini et al., 2010; Sousa et al., 2012; Kostrzewa et al., 2013).

\section{Analytic-recirculation method}

The analytic-recirculation method is almost similar to the analytic-static method, but there is a small difference between these two methods. In fact, there is a backflow loop for the equilibrium vessel in the analytic-recirculation method that is not present in the analytic-static method. This backflow has some advantages, for instance it improves mixing and facilitates sampling. In this method, the analysis of phase compositions is performed on small amounts of backflow samples collected through the online sampling valve that is connected to the measuring device.

The use of backflow in the analytic-recirculation method has some disadvantages such as a pressure drop and subsequent sedimentation of solute in the backflow loop. In this method, because of the utilization of recirculation pumps, the pressure changes and this is undesirable for equilibrium conditions. More details about this method are available in studies by $\mathrm{Yu}$ et al. (1992) and Kodama et al. (2004) who investigated phase equilibria, and Cabrera et al. (2015) and Iwai et al. (2004) who studied solubility.

\section{Analytic-flow method}

The analytic-flow method was initially developed for systems with temperature-sensitive components and for reaction systems. In this method, a preheated mixture with constant overall composition continuously flows into the equilibrium vessel and is separated into two phases with different densities. The light and heavy phases continuously exit from the top and bottom of the vessel, respectively, and they are analyzed after sampling.

The analytic-flow method has some advantages; for instance, it requires less time to achieve the equilibrium state, which reduces the residence time. Because of these characteristics, the changes in compositions are minimal, and thermal decomposition of components does not continue further. As the main advantage of the analytic-flow method, the sampling in this method is faster and easier than the sampling in other methods, and it does not disturb the equilibrium state. This method was used by Shimoyama et al. (2008) to investigate phase equilibria; it is applied by many other researchers (Suzuki et al., 1991; Xing et al., 2003; Ferri et al., 2004; Ghaziaskar and Kaboudvand, 2008; Li et al., 2010; Tang et al., 2011; Jin et al., 2012;
Li et al., 2013; Danlami et al., 2015; and Wu et al., 2016) to examine solubility.

\section{Analytic-saturation method}

The analytic-saturation method is used for determining the solubility of solids and liquids with high viscosity in supercritical fluids. A nonvolatile heavy phase, either solid or liquid, is loaded in equilibrium vessels and it remains as a stationary phase until the end of the experiment. Subsequently, a continuous flow of the supercritical fluid enters from the bottom of a vessel and, after reaching the saturation state, it exits from the top.

In the analytic-saturation method, the solubility of the heavy phase in the supercritical fluid is determined through sampling and analyzing the output fluid flow. In addition, it can be determined through measuring the total volume of the gas passing through the equilibrium vessel and through measuring the mass of the extracted solute. In this method, it is important to ensure that a saturated solvent is obtained at the output of the equilibrium vessel. Accordingly, adequate amounts of solute must be applied and the output flow rate must be set appropriately. The application of this method for determining solubility is reported by Pauchon et al. (2004) and Huang et al. (2005).

The use of the analytic method in multicomponent mixtures is its most important advantage. Fig. 5 shows the schematic of an apparatus used for determining fluid phase equilibrium using the analytic methods (recirculation method).

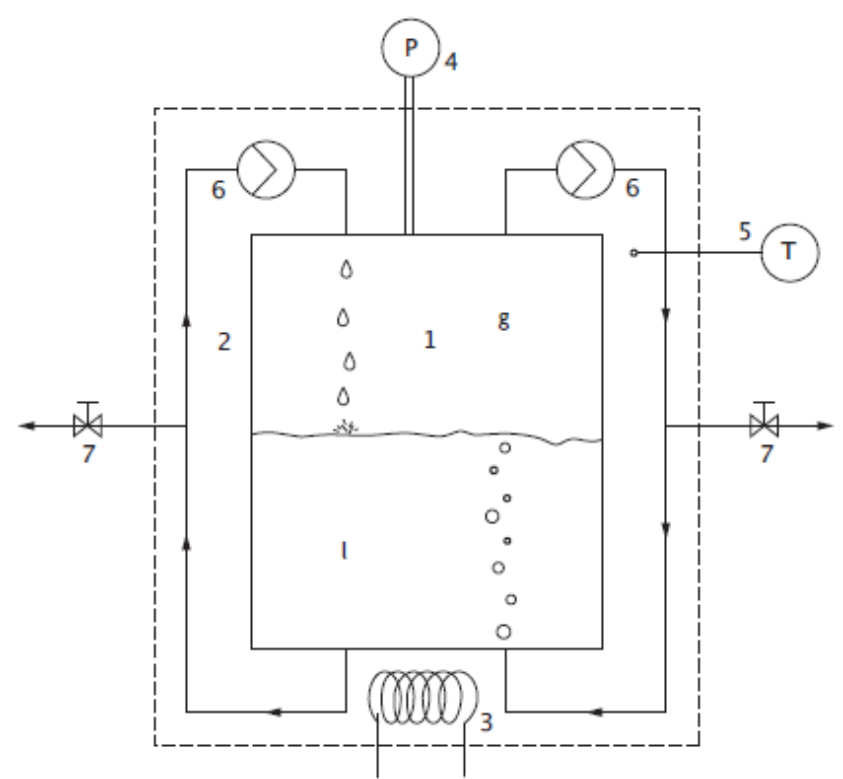

Figure 5. The schematic of an apparatus for determining fluid phase equilibrium using the analyticrecirculation method, (1) sample space, (2) pressure vessel, (3) heater, (4) manometer, (5) thermometer, (6) recirculation pumps, and (7) valves (Deiters and Kraska, 2012). 


\section{Synthetic methods}

In synthetic methods, a mixture with a specific composition is put under pressure in an equilibrium vessel to achieve a homogeneous phase at a constant temperature. In this process, it is necessary to control the temperature of the vessel. In order to obtain the desired pressure for the experiment, the volume of the vessel is changed by a movable piston.

In synthetic methods, the phase transition occurs as the result of changes in pressure under a constant temperature or vice versa. The phase changes can be monitored through visual observation using a visible cell or through observing changes in physical properties.

Synthetic methods are more favorable and economic because they do not require sampling and complex analytical tools. However, it should be noted that, in this method, it is difficult to detect the phase equilibrium and determine the solubility through visual observation. In fact, it becomes more challenging when coexisting phases have the same refractive indices and synthetic methods with optical detection tools cannot be used for this situation (Deiters and Kraska, 2012).

The utilization of synthetic methods for determining phase equilibrium is limited only to binary systems and these methods cannot be used for multicomponent mixtures. Therefore, in the multicomponent systems, tie lines cannot be determined without performing additional experiments. Fig. 6 presents the schematic

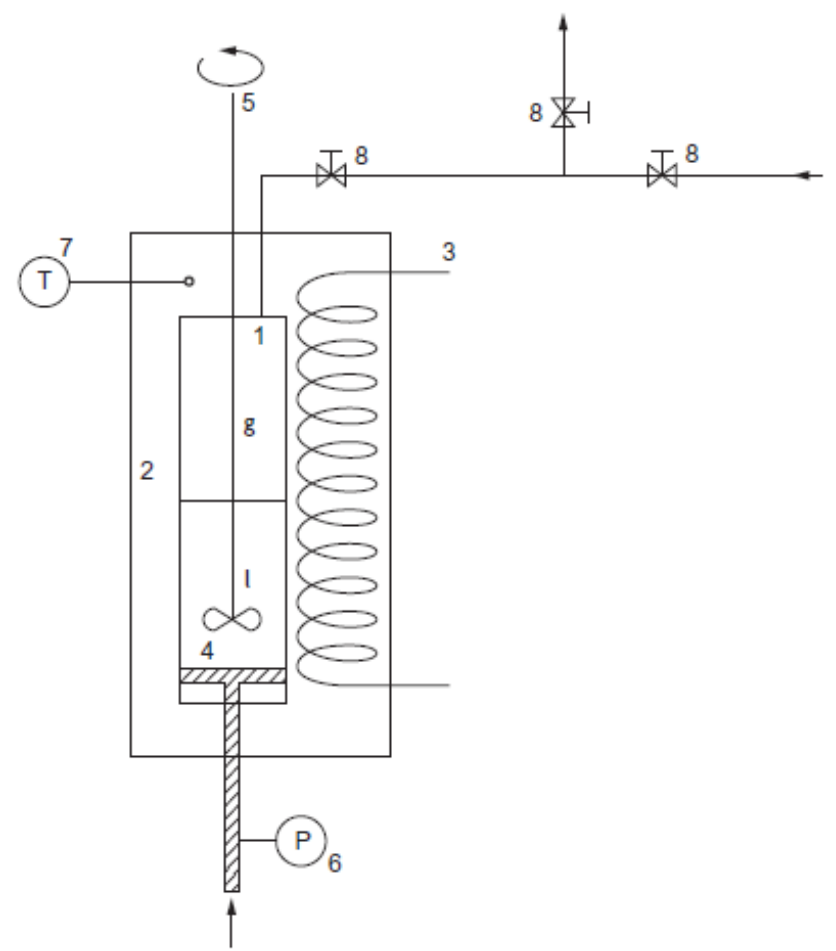

Figure 6. The Schematic of an apparatus for determining fluid phase equilibrium using the synthetic method, (1) sample space, (2) pressure vessel, (3) heater, (4) piston, (5) stirrer, (6) manometer, (7) thermometer, and (8) valves (Deiters and Kraska, 2012). of an apparatus for determining the phase equilibrium using synthetic methods.

The utilization of synthetic methods for determining high-pressure phase behavior and solubility is discussed by various researchers in many scientific texts (Bittrich et al., 1996; Crampon et al., 1999; Borg et al., 2001; Lazzaroni et al., 2004; Tsuji et al., 2004; Lazzaroni et al., 2006; Tenorio et al., 2012; Morère et al., 2013; Nielsen et al., 2015; Kouakou et al., 2016).

The gravimetric method is one of the synthetic methods commonly used for determining solubility in supercritical fluids. In this method, a small glass vessel with a specific amount of solute is placed in a pressurized vessel where it is in contact with the supercritical fluid. This glass vessel only allows dissolved solute to pass, and the solute particles cannot exit the equilibrium vessel before dissolving. After reaching the equilibrium state, the pressure of the vessel drops. In order to determine solubility, the residue of the solute is weighed. Typically, the gravimetric method is used together with the static method to determine solubility (Sabegh et al., 2012; Rajaei et al., 2013; Shojaee et al., 2013; Khayyat et al., 2015).

\section{Transient methods}

Transient methods are used for experimental determination of solubility and high-pressure phase behavior of fluids. These methods are also employed for determining the vapor or sublimation pressure of compounds with a very low volatility. Transient methods are divided into two categories: flow of matter and heat flow. When using a flow of matter transient method, the supercritical fluid is placed in contact with solute until it reaches the saturation state. Then, it is transferred from the cold trap and the solute is deposited. Afterward, solubility can be determined through measuring the mass of deposited solute and fluid flow rate (Deiters and Kraska, 2012).

In a heat flow transient method, the enthalpy of the system changes due to the phase transition, which in turn results in an easily recognizable change in temperature. More details about this method are reported by Deiters and Kraska (2012). Fig. 7 shows the schematic of an apparatus utilized for determining fluid phase equilibrium using the flow of matter method.

\section{High-pressure phase equilibria of fluids}

Equations of state play an important role in the thermodynamic modeling of high-pressure fluid phase equilibria. Utilization of the equations of state for phase equilibrium calculations has significant benefits, because they can be used for a wide range of pressure and temperature. Researchers have applied this method for modeling phase equilibria in mixtures with different 


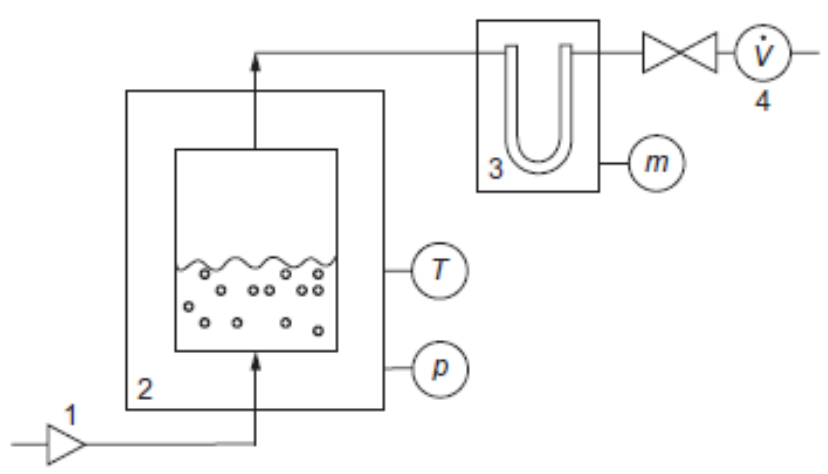

Figure 7. The schematic of an apparatus for determining fluid phase equilibrium using the flow of matter method, (1) compressor, (2) pressure vessel, (3) cold collector attached to precision scale, and (4) flow meter (Deiters and Kraska, 2012).

components. Equations of state can also be used for calculating phase equilibria without facing conceptual difficulties. Various types of phase equilibria can be studied using these equations. Different types of these phase equilibria are reviewed in the following section.

\section{Vapor-liquid equilibrium}

In the vapor-liquid equilibrium, the fugacity of each component in the vapor and liquid phases is equal. Therefore, the equilibrium criterion can be stated as:

$\mathrm{f}_{\mathrm{i}}^{\mathrm{V}}\left(\mathrm{T}, \mathrm{P}, \mathrm{y}_{\mathrm{i}}\right)=\mathrm{f}_{\mathrm{i}}^{\mathrm{L}}\left(\mathrm{T}, \mathrm{P}, \mathrm{x}_{\mathrm{i}}\right) \quad \mathrm{i}=1,2, \ldots, \mathrm{m}$

where $\mathrm{f}_{\mathrm{i}}^{\mathrm{V}}$ and $\mathrm{f}_{\mathrm{i}}^{\mathrm{L}}$ are the fugacity of component $i$ in vapor phase (supercritical fluid) and liquid phase, respectively. $\mathrm{y}_{i}$ and $\mathrm{x}_{\mathrm{i}}$ are the mole fraction of component $i$ in the vapor phase or supercritical fluid and liquid phase, respectively. $m$ is the number of components and $T, P$ are temperature and pressure of the system, respectively. Eq. (2) can be expressed in terms of fugacity coefficients as follows.

$\mathrm{y}_{\mathrm{i}} \varphi_{\mathrm{i}}^{\mathrm{V}} \mathrm{P}=\mathrm{x}_{\mathrm{i}} \varphi_{\mathrm{i}}^{\mathrm{L}} \mathrm{P}$

where $\varphi_{i}{ }^{\mathrm{V}}$ and $\varphi_{i}{ }^{\mathrm{L}}$ are the fugacity coefficients of component $i$ in the vapor phase or supercritical fluid and liquid phase, respectively. The fugacity coefficients of vapor and liquid phases can be calculated using exact thermodynamic relationships as below.

$$
\begin{aligned}
& \ln \varphi_{\mathrm{i}}^{\mathrm{V}}=\frac{1}{\mathrm{RT}} \int_{\mathrm{v}}^{\infty} \mathrm{V}^{\infty}\left[\left(\frac{\partial \mathrm{P}}{\partial \mathrm{n}_{\mathrm{i}}}\right)_{\mathrm{T}, \mathrm{V}, \mathrm{n}_{\mathrm{i} \neq \mathrm{j}}}-\frac{\mathrm{RT}}{\mathrm{V}}\right] \mathrm{dv}-\ln \left(\frac{\mathrm{Pv}^{\mathrm{V}}}{\mathrm{RT}}\right) \\
& \ln \varphi_{\mathrm{i}}^{\mathrm{L}}=\frac{1}{\mathrm{RT}} \int_{\mathrm{v}}^{\infty}\left[\left(\frac{\partial \mathrm{P}}{\partial \mathrm{n}_{\mathrm{i}}}\right)_{\mathrm{T}, \mathrm{V}, \mathrm{n}_{\mathrm{i} \neq \mathrm{j}}}-\frac{\mathrm{RT}}{\mathrm{V}}\right] \mathrm{dv}-\ln \left(\frac{\mathrm{PV}^{\mathrm{L}}}{\mathrm{RT}}\right)
\end{aligned}
$$

where $R$ is the gas constant, $v^{\mathrm{V}}$ and $v^{\mathrm{L}}$ are the molar volume of the vapor phase and liquid phase, respectively. $n_{i}$ and $n_{j}$ are the numbers of moles of components $i$ and $j$, respectively. The fugacity coefficients in the vapor and liquid phases can be calculated using an equation of state.

Since sizes, structures, and intermolecular forces of components in a mixture are not significantly different, a conventional cubic equation of state can be used for the evaluation of the phase behavior of highpressure systems. Among cubic equations, the PengRobinson and Soave-Redlich-Kowang equations of state are widely used for determining high-pressure phase equilibria (Stevens et al., 1997; Adrian et al., 1998; Liao et al., 2010; Hou et al., 2012; Brandalize et al., 2014; Machida et al., 2014; Pereira et al., 2014). In addition to the cubic equations of state, CPA and GC equations of state are also used to predict thermodynamic properties and high-pressure phase behavior of fluids (Espinosa et al., 2002; FernándezRonco et al., 2010; Keshtkari et al., 2013; Masoodiyeh et al., 2013).

\section{Solid-supercritical fluid equilibrium}

In solid-supercritical fluid equilibrium, the fugacity of component $i$ in the supercritical fluid can be calculated using the following equation.

$$
\mathrm{f}_{\mathrm{i}}^{\mathrm{SCF}}\left(\mathrm{T}, \mathrm{P}, \mathrm{y}_{\mathrm{i}}\right)=\mathrm{y}_{\mathrm{i}} \varphi_{\mathrm{i}}^{\mathrm{SCF}} \mathrm{P}
$$

where the SCF superscript refers to the supercritical fluid. In order to calculate the fugacity of component $i$ in the solid phase, it is assumed that the solid phase is completely pure. Accordingly, the following equation can be used.

$\mathrm{f}_{\mathrm{i}}^{\mathrm{S}}(\mathrm{T}, \mathrm{P})=\mathrm{P}_{\mathrm{i}}^{\text {sat }} \varphi_{\mathrm{i}}^{\text {sat }} \exp \left[\frac{\left(\mathrm{P}-\mathrm{P}_{\mathrm{i}}^{\mathrm{sat}}\right) \mathrm{v}_{\mathrm{i}}^{\mathrm{S}}}{\mathrm{RT}}\right]$

In Eq. (7), $\mathrm{P}_{\mathrm{i}}^{\text {sat }}$ is the sublimation pressure of pure solid at the temperature of the system, $\varphi_{i}^{\text {sat }}$ is the fugacity coefficient at $\mathrm{P}_{i}^{\text {sat }}$ and temperature of the system, $v_{i}^{\mathrm{S}}$ is the molar volume of pure solid, and the exponential term represents the Poynting correction factor for the fugacity of pure solid. It can be assumed that the fugacity coefficient of pure solid is equal to one. Hence, considering the equilibrium criterion, the solid solubility in the supercritical fluid phase can be determined using the following equation.

$$
\mathrm{y}_{\mathrm{i}}=\frac{\mathrm{P}_{\mathrm{i}}^{\mathrm{sat}} \exp \left[\frac{\left(\mathrm{P}-\mathrm{P}_{\mathrm{i}}^{\mathrm{sat}}\right) \mathrm{v}_{\mathrm{i}}^{\mathrm{S}}}{\mathrm{RT}}\right]}{\varphi_{\mathrm{i}}^{\mathrm{SCF}} \mathrm{P}}
$$


As shown in Eq. (8), upon increasing the pressure under a constant temperature, solubility in the supercritical fluid should increase as well. This is due to a sharp decrease in the fugacity coefficient of the supercritical fluid, which occurs as the result of an increase in pressure, especially near the critical point of the supercritical fluid.

\section{Solid-liquid-vapor equilibrium}

The equilibrium criterion for coexisting phases of solid, liquid, and vapor (supercritical fluid) can be easily explained by considering the solid-vapor and vapor-liquid equilibria.

$\mathrm{f}_{\mathrm{i}}^{\mathrm{S}}(\mathrm{T}, \mathrm{P})=\mathrm{f}_{\mathrm{i}}^{\mathrm{V}}\left(\mathrm{T}, \mathrm{P}, \mathrm{y}_{\mathrm{i}}\right)$

$f_{i}^{L}\left(T, P, x_{i}\right) \quad f_{i}^{V}\left(T, P, y_{i}\right)$

According to the Gibbs phase rule, the two above mentioned equations can be applied for a binary system without chemical reactions when two variables, such as temperature and pressure, are set at specific values. Thus, the equilibrium criterion for solid, liquid, and vapor phases can be expressed through the following equation.

$f_{i}^{S}(T, P)=f_{i}^{L}\left(T, P, x_{i}\right)=f_{i}^{V}\left(T, P, y_{i}\right)$

In the solid-liquid-vapor equilibrium in a binary system without chemical reactions, the equilibrium equations can be applied using only one variable such as temperature or pressure. The three-phase equilibrium under high-pressure conditions in multicomponent systems is comprehensively studied by Lemert and Johnston (1989).

\section{Phase stability calculations}

Phase stability analysis is one of the important items to be considered in phase equilibrium calculations. Adequate knowledge about the number and type of stable phases in the equilibrium state plays a crucial role in calculating the phase equilibrium and determining solubility. The fluid phase is in a stable state when it is resistant to small changes in thermodynamic properties. On the other hand, it is in an unstable phase when it breaks into one or more phases due to such changes. The phase stability is highly dependent on the operating conditions, which can be either favorable or unfavorable.

When an isolated system operates in a stable equilibrium state, the total Gibbs free energy of the system is minimal under a constant pressure and temperature. In other words, the Gibbs free energy of the system is minimized during the phase stability.

Lupis and Gaye (1971) presented a stability function in order to study the thermodynamic properties of multicomponent solutions. For binary solutions, their stability function $(\Psi)$ is defined as follows (Lupis and Gaye, 1971).

$\Psi=X_{1} X_{2} \frac{d^{2}\left(G_{m} / R T\right)}{d X_{2}^{2}}$

When the stability function is positive $(\Psi>$ 0 ), the solution is stable with respect to small changes in the composition. As the stability function becomes negative $(\Psi<0)$, the solution becomes unstable. Finally, the stability function becomes zero at the spinodal compositions $(\Psi=0)$. For a regular solution, the stability function can be expressed as follows.

$\Psi=1-\left(\frac{2 \Omega}{\mathrm{RT}}\right) \mathrm{X}_{1} \mathrm{X}_{2}$

where $\Omega$ represents the interaction between atoms 1 and 2 in the solution. The stability function can be used for ternary solutions and those with more components.

Gupta et al. (1991) presented a method for phase stability analysis. Their method seeks to minimize the Gibbs free energy and can be applied for systems with/ without chemical reactions. In the mentioned method, the presence or absence of a phase in the equilibrium state is determined by solving equilibrium and stability problems, simultaneously.

The tangent plane distance method (TPD), presented by Michelsen (1982a; 1982b) is another approach for stability analysis. In this method, at a given temperature and pressure of a mixture with $m$ component, the stability criterion can be expressed by Eq. (14) (Michelsen, 1982a).

$$
\operatorname{TPD}(\mathrm{x})=\sum_{\mathrm{i}} \mathrm{x}_{\mathrm{i}}\left(\mu_{\mathrm{i}}(\mathrm{x})-\mu_{\mathrm{i}}^{0}\right) \geq 0
$$

where geometrically $\operatorname{TPD}(x)$ is the vertical distance from the tangent hyperplane to the molar Gibbs energy surface in composition $z$ to the energy surface in composition $x$, and $\mu_{\mathrm{i}}{ }^{0}$ is the chemical potential of component $i$ in the mixture (Michelsen, 1982a). When an equation of state is used, fugacity coefficients are easily applied and the constraints are reduced as well. By defining a new variable, $X_{i}$, representing the number of moles of component $i$, Michelsen (1982a) expressed the stability criterion by Eq. (15).

$$
\operatorname{TPD}(\mathrm{x})=1+\sum_{\mathrm{i}} \mathrm{X}_{\mathrm{i}}\left(\ln \mathrm{X}_{\mathrm{i}}+\ln \varphi_{\mathrm{i}}(\mathrm{x})-\ln \mathrm{z}_{\mathrm{i}}-\ln \varphi_{\mathrm{i}}(\mathrm{z})-1\right) \geq 0
$$

In Eq. (15), $\mathrm{z}_{\mathrm{i}}$ is the composition of feed components, $\varphi_{i}(\mathrm{z})$ is the fugacity coefficient of component $i$ in the 
feed composition, and $\varphi_{i}(\mathrm{x})$ is the fugacity coefficient of components in composition $x$. $\mathrm{X}_{\mathrm{i}}$ is the number of moles, hence, the only limitation is $X_{i}>0$, and Eq. (15) can be minimized just based on the number of moles.

Phase stability can be determined through considering the sign of the minimized TPD function. When the value of this function is positive or equal to zero, the system is stable. When its value is negative, the system is unstable and can be broken into two or more new stable phases (Michelsen, 1982a). Given the significance of the phase stability analysis in equilibrium calculations, many efforts have been made to provide different algorithms for calculating the stability (Zhu et al., 2000; Rahman et al., 2009; Henderson et al., 2011; Nichita and Petitfrere, 2013; Staudt et al., 2013).

\section{Modeling solubility in supercritical fluids}

It is expensive, complicated, and in some cases impossible to experimentally investigate and determine solubility in supercritical fluids over various ranges of temperature and pressure. Hence, many efforts have been made to present and develop mathematical models to estimate solubility of a solute in supercritical fluids at the equilibrium state. Efforts made to model solubility can be divided into three main categories, including semiempirical models, equations of statebased methods, and solubility parameter model. In the following section, these three types of methods are discussed.

\section{Semiempirical models}

Semiempirical models are widely used for determining solubility. In these methods, the solubility is predicted based on the correlation between experimental data. These models present mathematical relationships, and they are more accurate than other methods. In these models, experimental data on solubility are essential for calculating the correlation, and in some cases it is the main limitation of the models.

The Chrastil model (Chrastil, 1982) was the first semiempirical model that correlated solubility of solids in a supercritical fluid. This model investigates the relationship between the solubility of a solute in a supercritical fluid and the density of the pure supercritical fluid under a given temperature. The Chrastil model was developed based on the theory of chemical association and can be expressed by Eq. (16) (Chrastil, 1982).

$\ln \mathrm{S}=\mathrm{A}_{1}+\frac{\mathrm{A}_{2}}{\mathrm{~T}}+\mathrm{A}_{3} \ln \rho$

where $S$ is the solubility $\left(\mathrm{kg} \mathrm{m}^{-3}\right)$ of materials in a supercritical fluid, $\rho$ is the solvent density $\left(\mathrm{kg} \mathrm{m}^{-3}\right)$,
$T$ is the temperature $(\mathrm{K}), A_{1}$ is a function of the molar mass of the solute, $A_{2}$ is a function of the enthalpy of solvation and enthalpy of vaporization, and $A_{3}$ is the association number, that represents the number of molecules of supercritical fluid in a solvated complex. The Chrastil equation is not valid for a wide range of temperatures and for a solubility value higher than $100-200 \mathrm{~kg} \mathrm{~m}^{-3}$ (Sparks et al., 2008). Because of these limitations, this equation has undergone some modifications.

Sung and Shim (1999) added a new term to the Chrastil model and presented a new model to estimate the solubility of solutes in a supercritical fluid as follows:

$$
\ln y=A_{1}+\frac{A_{2}}{T}+\left(A_{3}+\frac{A_{4}}{T}\right) \ln \rho
$$

where $y$ is the solubility (mole fraction) and $\rho$ is the supercritical fluid density $\left(\mathrm{kg} \cdot \mathrm{m}^{-3}\right)$.

Adachi and Lu (1983) also modified the Chrastil model through considering the role of density on the association number and introduced a new model for solubility estimation as follows:

$$
\ln S=A_{1}+\left(A_{2}+A_{3} \rho+A_{4} \rho^{2}\right) \ln \rho+\frac{A_{5}}{T}
$$

Sparks et al. (2008) presented another model based on Adachi and Lu's model that included the effect of density on the association number as follows:

$\ln S=A_{1}+\left(A_{2}+A_{3} \rho+A_{4} \rho^{2}\right) \ln \rho+\frac{A_{5}}{T}+\frac{A_{6}}{T^{2}}$

Bartle et al. (1991) also offered a model, presented in Eq. (20), to determine the solubility of solids in a supercritical fluid.

$\ln \left(\frac{y P}{P_{\text {ref }}}\right)=A_{1}+\frac{A_{2}}{T}+A_{3}\left(\rho-\rho_{\text {ref }}\right)$

where $\mathrm{P}_{\text {ref }}$ and $\rho_{\text {ref }}$ are the pressure and density of a reference point, respectively.

Gordillo et al. (1999) introduced a new model to evaluate solubility in terms of temperature and pressure as follows:

$\ln \mathrm{y}=\mathrm{A}_{1}+\mathrm{A}_{2} \mathrm{P}+\mathrm{A}_{3} \mathrm{P}^{2}+\mathrm{A}_{4} \mathrm{PT}+\mathrm{A}_{5} \mathrm{~T}+\mathrm{A}_{6} \mathrm{~T}^{2}$

Méndez-Santiago and Teja (1999) developed a semiempirical model based on the theory of dilute solutions, presented in Eq. (22), to determine solubility. 
$\mathrm{T} \ln (\mathrm{yP})=\mathrm{A}_{1}+\mathrm{A}_{2} \mathrm{~T}+\mathrm{A}_{3} \rho$

Kumar and Johnston (1988) also introduced a model for evaluating solubility in terms of temperature and density as follows:

$\ln \mathrm{y}=\mathrm{A}_{1}+\frac{\mathrm{A}_{2}}{\mathrm{~T}}+\mathrm{A}_{3} \rho$

Another semiempirical model to determine solubility is a model presented by Del Valle and Aguilera (1988), which puts emphasis on the role of temperature. This model can be expressed as follows:

$\ln \mathrm{S}=\mathrm{A}_{1}+\frac{\mathrm{A}_{2}}{\mathrm{~T}}+\frac{\mathrm{A}_{3}}{\mathrm{~T}^{2}}+\mathrm{A}_{4} \ln \rho$

Equations introduced by $\mathrm{Yu}$ et al. (1994) and Jouyban et al. (2002) are other semiempirical equations for determining solubility and they are expressed by Eqs. (25) and (26), respectively.

$\mathrm{y}=\mathrm{A}_{1}+\mathrm{A}_{2} \mathrm{P}+\mathrm{A}_{3} \mathrm{P}^{2}+\mathrm{A}_{4} \mathrm{PT}(1-\mathrm{y})+\mathrm{A}_{5} \mathrm{~T}+\mathrm{A}_{6} \mathrm{~T}^{2}$

$\ln \mathrm{y}=\mathrm{A}_{1}+\mathrm{A}_{2} \mathrm{P}+\mathrm{A}_{3} \mathrm{P}^{2}+\mathrm{A}_{4} \mathrm{PT}+\mathrm{A}_{5} \frac{\mathrm{T}}{\mathrm{P}}+\mathrm{A}_{6} \ln \rho$

The coefficients $A_{1}$ to $A_{6}$ in the semiempirical equations are empirical constants that can be determined through data regression.

In order to select and develop an appropriate model, it might be helpful to compare the accuracy of these models in predicting solubility in supercritical fluids. To this end, Tabernero et al. (2010) compared the accuracy of semiempirical models in predicting drug solubility of 27 various solutes.

Semiempirical models are commonly applied to determine solubility in supercritical fluids. Table (1) presents a comprehensive review of these models used for determining the solubility of various compounds in supercritical carbon dioxide. According to the results, these different models show different levels of accuracy in predicting solubility.

In these semiempirical models, solubility is dependent on temperature. The effect of temperature on solubility is complex and the crossover of the solubility isotherm occurs when pressure is considered as a variable. This phenomenon is influenced by the density of solvent and vapor pressure of the solute. In fact, the vapor pressure increases as a result of an increase in temperature and solubility; on the contrary, there is a reduction in density and solvent power. Consequently, solubility decreases because the density of the solvent is the dominant factor. After passing the crossover area, upon increasing the temperature, the vapor pressure of the solute becomes a dominant factor and the solubility increases. However, this opposite behavior is often attributed to solvent density and solute vapor pressure.

\section{Equation of state-based methods}

In order to model solubility in a supercritical fluid system, it is common to use equations of state and calculate the fugacity of a component in the liquid or solid phase (solute) and supercritical fluid (solvent). When equations of state are applied for modeling solubility, the characteristics of the supercritical fluid become similar to the characteristics of a high-pressure gas. Accordingly, cubic equations of state such as Peng-Robinson (PR), Soave-Redlich-Kwong (SRK), Valderrama-Patel-Teja (VPT), and EsmaeilzadehRoshanfekr (ER) with various mixing rules such as van der Waals, Panagiotopoulos-Reid, Wong-Sandler, and Orbey-Sandler are widely used for modeling solubility (Mendes et al., 1999; Madras et al., 2003; Jha and Madras, 2004; Valderrama and Alvarez, 2004; Coimbra et al., 2006; Shamsipur et al., 2008; Esmaeilzadeh et al., 2009; Yazdizadeh et al., 2011; Yazdizadeh et al., 2012).

The efficacy of equations of state in predicting solubility near the critical point helps to select an appropriate equation for determining solubility. In addition to cubic equations of state, the Virial equation of state (Harvey, 1997; Schultz et al., 2010) and the SAFT equation of state (Yang and Zhong, 2005; Anvari and Pazuki, 2014) are also used to calculate solid solubility in supercritical fluids.

Comparing the efficacy of these equations in predicting solubility, it can be observed that the SAFT equation of state provides more accurate results than cubic equations of state. In addition, it is more reliable for modeling the solubility of solids in supercritical fluids.

Predicting solubility of solids in supercritical fluids using equations of state is more complex than the utilization of semiempirical models. Equations of state require more data on the solute such as critical properties and sublimation pressure, and such data must be extracted from the scientific literature or estimations.

The data on properties of the solute, especially for compounds with complex structures, are not available; therefore, different approaches such as group contribution methods are commonly used (Cortesi et al., 1999; Tomberli et al., 2006). Given the limitations of equations of state, the accuracy of these equations in predicting solubility is less than semiempirical models.

\section{Solubility parameter model}

In the solubility parameter model, the supercritical fluid is considered as a liquid solvent and the activity 
Table 1. Comparison of semiempirical models for determining solubility in various systems.

\begin{tabular}{|c|c|c|c|c|c|}
\hline Model & Exampel of solute & Temperature (K) & Pressure (bar) & AARD $\%$ & Ref \\
\hline \multirow[t]{11}{*}{ Chrastil } & Norfloxacin & $308.2-328.2$ & $100-303$ & 33.90 & (Chim et al., 2012) \\
\hline & Ofloxacin & $308.2-328.2$ & $100-303$ & 22.10 & (Chim et al., 2012) \\
\hline & Cefixime trihydrate & $308-328$ & $183-335$ & 2.57 & (Khamda et al., 2013) \\
\hline & Oxymetholone & $308-328$ & $121-305$ & 5.95 & (Khamda et al., 2013) \\
\hline & Artemisinin & $313-333$ & $110-310$ & 8.32 & (Gong and $\mathrm{Cao}, 2009$ ) \\
\hline & 1-amino-4-hydroxyanthraquinone & $323.15-383.15$ & $125-250$ & 15.00 & (Tamura and Alwi, 2015) \\
\hline & 1-hydroxy-4-nitroanthraquinone & $323.15-383.15$ & $125-250$ & 10.60 & (Tamura and Alwi, 2015) \\
\hline & Thymol & $308-323$ & $78-250$ & 17.82 & (Milovanovic et al., 2013) \\
\hline & bisphenol A & $308-328$ & $110-210$ & 8.25 & (Jin et al., 2013) \\
\hline & $\mathrm{N}, \mathrm{N}$-dimethylformamide diethyl acetal & $313-353$ & $78-133$ & 6.10 & (Zhang et al., 2014) \\
\hline & o-nitrobenzoic acid & $308-328$ & $100-210$ & 5.91 & (Tang et al., 2012) \\
\hline \multirow{5}{*}{$\begin{array}{l}\text { Sung } \\
\text { and } \\
\text { Shim }\end{array}$} & 1-amino-4-hydroxyanthraquinone & $323.15-383.15$ & $125-250$ & 7.60 & (Tamura and Alwi, 2015) \\
\hline & 1-hydroxy-4-nitroanthraquinone & $323.15-383.15$ & $125-250$ & 5.10 & (Tamura and Alwi, 2015) \\
\hline & bisphenol A & $308-328$ & $110-210$ & 3.39 & (Jin et al., 2013) \\
\hline & $\mathrm{N}, \mathrm{N}$-dimethylformamide diethyl acetal & $313-353$ & $78-133$ & 4.63 & (Zhang et al., 2014) \\
\hline & o-nitrobenzoic acid & $308-328$ & $100-210$ & 4.30 & (Tang et al., 2012) \\
\hline \multirow{2}{*}{$\begin{array}{c}\text { Adachi } \\
\text { and } \\
\text { Lu }\end{array}$} & grape seed oil & $313-343$ & $200-500$ & 0.26 & (Duba and Fiori, 2016) \\
\hline & bisphenol A & $308-328$ & $110-210$ & 5.45 & (Jin et al., 2013) \\
\hline \multirow{3}{*}{$\begin{array}{l}\text { Sparks } \\
\text { et al. }\end{array}$} & Norfloxacin & $308.2-328.2$ & $100-303$ & 26.90 & (Chim et al., 2012) \\
\hline & Ofloxacin & $308.2-328.2$ & $100-303$ & 8.60 & (Chim et al., 2012) \\
\hline & grape seed oil & $313-343$ & $200-500$ & 0.26 & (Duba and Fiori, 2016) \\
\hline \multirow{6}{*}{$\begin{array}{l}\text { Bartle } \\
\text { et al. }\end{array}$} & Norfloxacin & $308.2-328.2$ & $100-303$ & 37.30 & (Chim et al., 2012) \\
\hline & Ofloxacin & $308.2-328.2$ & $100-303$ & 23.10 & (Chim et al., 2012) \\
\hline & Cefixime trihydrate & $308-328$ & $183-335$ & 3.73 & (Khamda et al., 2013) \\
\hline & Oxymetholone & $308-328$ & $121-305$ & 5.86 & (Khamda et al., 2013) \\
\hline & grape seed oil & $313-343$ & $200-500$ & 1.46 & (Duba and Fiori, 2016) \\
\hline & bisphenol A & $308-328$ & $110-210$ & 8.67 & (Jin et al., 2013) \\
\hline \multirow{2}{*}{$\begin{array}{c}\text { Gordillo } \\
\text { et al. }\end{array}$} & 1-chloro-2,4-dinitrobenzene & $308-313$ & $95-145$ & 1.27 & (Reddy and Madras, 2011) \\
\hline & m-dinitrobenzene & $308-328$ & $95-145$ & 8.52 & (Reddy and Madras, 2011) \\
\hline Mendez- & Norfloxacin & $308.2-328.2$ & $100-303$ & 38.10 & (Chim et al., 2012) \\
\hline Santiago- & Ofloxacin & $308.2-328.2$ & $100-303$ & 23.20 & (Chim et al., 2012) \\
\hline \multirow[t]{9}{*}{ Teja } & Cefixime trihydrate & $308-328$ & $183-335$ & 3.56 & (Khamda et al., 2013) \\
\hline & Oxymetholone & $308-328$ & $121-305$ & 6.27 & (Khamda et al., 2013) \\
\hline & Spironolactone & $308-338$ & $160-400$ & 13.10 & (Hezave et al., 2013) \\
\hline & Artemisinin & $313-333$ & $110-310$ & 8.33 & (Gong and Cao, 2009) \\
\hline & grape seed oil & $313-343$ & $200-500$ & 1.46 & (Duba and Fiori, 2016) \\
\hline & bisphenol A & $308-328$ & $110-210$ & 6.74 & (Jin et al., 2013) \\
\hline & 1-chloro-2,4-dinitrobenzene & $308-313$ & $95-145$ & 7.25 & (Reddy and Madras, 2011) \\
\hline & m-dinitrobenzene & $308-328$ & $95-145$ & 11.50 & (Reddy and Madras, 2011) \\
\hline & o-nitrobenzoic acid & $308-328$ & $100-210$ & 4.68 & (Tang et al., 2012) \\
\hline Kumar & Cefixime trihydrate & $308-328$ & $183-335$ & 2.49 & (Khamda et al., 2013) \\
\hline \multirow[t]{7}{*}{ and Johnston } & Oxymetholone & $308-328$ & $121-305$ & 9.20 & (Khamda et al., 2013) \\
\hline & 1-amino-4-hydroxyanthraquinone & $323.15-383.15$ & $125-250$ & 10.60 & (Tamura and Alwi, 2015) \\
\hline & 1-hydroxy 4-nitroanthraquinone & $323.15-383.15$ & $125-250$ & 6.80 & (Tamura and Alwi, 2015) \\
\hline & grape seed oil & $313-343$ & $200-500$ & 0.26 & (Duba and Fiori, 2016) \\
\hline & bisphenol A & $308-328$ & $110-210$ & 6.71 & (Jin et al., 2013) \\
\hline & Spironolactone & $308-338$ & $160-400$ & 12.20 & (Hezave et al., 2013) \\
\hline & o-nitrobenzoic acid & $308-328$ & $100-210$ & 6.61 & (Tang et al., 2012) \\
\hline \multirow{2}{*}{$\begin{array}{c}\text { Dell Valle } \\
\text { and Aguilera }\end{array}$} & Thymol & $308-323$ & $78-250$ & 16.27 & (Milovanovic et al., 2013) \\
\hline & grape seed oil & $313-343$ & $200-500$ & 0.79 & (Duba and Fiori, 2016) \\
\hline \multirow[t]{2}{*}{ Yu et al. } & grape seed oil & $313-343$ & $200-500$ & 0.56 & (Duba and Fiori, 2016) \\
\hline & bisphenol A & $308-328$ & $110-210$ & 3.01 & (Jin et al., 2013) \\
\hline Jouyban- & $\mathrm{N}, \mathrm{N}$-dimethylformamide diethyl acetal & $313-353$ & $78-133$ & 4.56 & (Zhang et al., 2014) \\
\hline Chan-Foster & o-nitrobenzoic acid & $308-328$ & $100-210$ & 6.03 & (Tang et al., 2012) \\
\hline
\end{tabular}

coefficient at infinite dilution is used to calculate the amount of non-ideality for solute-solvent equilibrium. Considering component 2 as a solute in a binary system, the mole fraction of solute in a supercritical solvent is calculated using the following equation.

$\mathrm{y}_{2}=\frac{\mathrm{f}_{2}^{\mathrm{S}}}{\mathrm{f}_{2}^{\mathrm{L}} \gamma_{2}^{\infty}}$ where $\gamma_{2}^{\infty}$ is the activity coefficient of the solute at infinite dilution. The relationship between fugacity of the solute in the solid phase $\left(\mathrm{f}_{2}^{\mathrm{S}}\right)$ and fugacity of the solute in the liquid phase $\left(\mathrm{f}_{2}^{\mathrm{L}}\right)$ can be expressed by Eq. (28).

$$
\ln \frac{\mathrm{f}_{2}^{\mathrm{S}}}{\mathrm{f}_{2}^{\mathrm{L}}}=\frac{\Delta \mathrm{H}_{2}^{\mathrm{f}}}{\mathrm{R}}\left(\frac{1}{\mathrm{~T}_{2, \mathrm{~m}}}-\frac{1}{\mathrm{~T}}\right)
$$


where $\Delta \mathrm{H}_{2}{ }^{\mathrm{f}}$ and $\mathrm{T}_{2, \mathrm{~m}}$ are the heat of fusion and melting temperature of the solute, respectively. The activity coefficient at infinite dilution is calculated using the regular solution model and Eq. (29).

$$
\ln \gamma_{2}^{\infty}=\left(\frac{\mathrm{v}_{2}}{\mathrm{RT}}\right)\left(\delta_{1}-\delta_{2}\right)^{2}+1-\left(\frac{\mathrm{v}_{2}}{\mathrm{v}_{1}}\right)+\ln \left(\frac{\mathrm{v}_{2}}{\mathrm{v}_{1}}\right)
$$

where $\delta_{\mathrm{i}}$ is the solubility parameter and is defined by the following equation.

$$
\delta_{\mathrm{i}}=\left(\frac{\Delta \mathrm{U}_{\mathrm{i}}^{\mathrm{vap}}}{\mathrm{v}_{\mathrm{i}}}\right)^{0.5}
$$

where $\Delta \mathrm{U}_{i}^{\text {vap }}$ and $v_{i}$ are the internal energy change of vaporization and molar volume of the solute, respectively. Considering the equations presented, the mole fraction of a solute can be calculated by Eq. (31).

$$
\ln \mathrm{y}_{2}=\frac{\Delta \mathrm{H}_{2}^{\mathrm{f}}}{\mathrm{R}}\left(\frac{1}{\mathrm{~T}_{2, \mathrm{~m}}}-\frac{1}{\mathrm{~T}}\right)-\left(\frac{\mathrm{v}_{2}}{\mathrm{RT}}\right)\left(\delta_{1}-\delta_{2}\right)^{2}-1+\left(\frac{\mathrm{v}_{2}}{\mathrm{v}_{1}}\right)-\ln \left(\frac{\mathrm{v}_{2}}{\mathrm{v}_{1}}\right)
$$

In many scientific papers, the regular solution model coupled with Flory-Huggins theory is used for calculating the solubility of solids in supercritical fluids (Cheng et al., 2002; Su and Chen, 2007; Su et al., 2011; Huang et al., 2013; Takeshita and Sato, 2002).

\section{Molecular simulation of solubility}

In order to determine the solubility of various materials in supercritical fluids using experimental methods, it is necessary to use advanced equipment that can be extremely expensive. In addition, in these methods, it is of great importance to have skilled experts for sampling and extraction of experimental data. Furthermore, it is worth noting that, due to operational limitations, it is difficult and in some cases impossible to obtain experimental data in a wide range of temperature and pressure. In comparison with experimental methods, only a computer is required for simulation; moreover, given the speed of data processing, much money and time are saved. In simulation methods, it is also possible to study the system in arbitrary conditions without any restriction.

The simulation of molecular phenomena is performed in three steps: designing the model, calculating the trajectory, and analyzing the trajectory. Among these steps, the second step (calculating the trajectory) is the most important step. In other words, the type of the simulation method is determined on the basis of the method for calculating the position of different molecules with respect to a coordinated origin. When these positions are determined by solving the equations of motion, it is time dependent and the method is known as the molecular dynamics simulation method. When these positions are obtained randomly and independent of time, the method is called a Monte Carlo simulation method.

Molecular simulation methods are widely used for systems containing supercritical fluid to predict solubility and study the phase behavior of different materials. In comparison with the equation of statebased methods, molecular simulation methods have more advantages such as utilization of physical models and the ability to apply mixtures without using additional parameters.

Molecular simulation methods are based on statistical mechanics and highlight the relationship between the results of microscopic simulation of a system and its visible macroscopic properties. These methods are performed in a distinct ensemble of statistical mechanics with a series of state variables such as the number of particles $(N)$, volume $(V)$, energy $(E)$, and temperature $(T)$.

\section{Molecular dynamics simulation method}

Molecular dynamics is a branch of mathematical physics. In this method, the interactions between atoms and molecules are simulated by a computer within a given period of time, based on the laws of physics. Since molecular systems generally contain a large number of particles, it is not possible to determine the characteristics of complex systems. Nevertheless, molecular dynamics simulations solve this problem by a computational method. This method is extensively used in materials science and molecular biology (Deuflhard et al., 2012; Mori et al., 2016; Sofronova et al., 2017).

Molecular dynamics simulation presents valuable information on the microscopic level, including the position and velocity of atoms. In order to convert this microscopic information to visible macroscopic properties such as pressure, energy, and heat capacity, it is necessary to utilize statistical mechanics. Molecular dynamics simulation utilizes the equation of motion of particles and analyzes mathematical relationships. In this method, numerical solutions of equations of motion for the particles are performed and trajectories of particles in different time steps are achieved. Finally, the speed and position of a particle at every time step is determined. In other words, this computational method calculates the time-dependent behavior of a molecular system and provides some information about disturbances and structural changes in these systems. The natural ensemble for molecular dynamics simulation is micro-canonical ensemble or NVE.

Potential energy functions and force fields play a great role in this method. In fact, the accuracy of properties determined by the molecular dynamics 
simulation depends highly on the precision of the potential energy functions that are used in this method.

\section{Potential energy functions and force fields}

One of the main issues in molecular dynamics simulations is the status of a system at the molecular level, which can be determined only through the analysis of the position and instant momentum of particles. Molecular dynamics simulation calculates the movement of molecules within a sample for different states of the system, including gas, liquid, and solid. In this method, position and speed functions of the particles are assumed to be independent of time and are called Hamiltonian function. Based on the Born-Oppenheimer approximation, the Hamiltonian of a system can be considered as a function of core changes, and it is assumed that the fast movement of electrons occurs in an average state. The Hamiltonian of a system is determined based on the sum of the total potential and kinetic energy, and is defined as follows.

$$
\begin{aligned}
& H\left(p^{N}, q^{N}\right)=K\left(p^{N}\right)+U\left(q^{N}\right) \\
& p^{N}=\left(p_{1}, p_{2}, \ldots, p_{N}\right), q^{N}=\left(q_{1}, q_{2}, \ldots, q_{N}\right)
\end{aligned}
$$

where $q$ and $p$ are the coordinate system and momentum of molecules, respectively, and $H$ is the Hamiltonian. In order to apply the Hamiltonian, it is essential to calculate forces and torques on a particle. The forces are determined by Eq. (34).

$$
\mathrm{F}_{\mathrm{i}}=-\frac{\partial \mathrm{H}}{\partial \mathrm{r}_{\mathrm{i}}}=-\frac{\partial \mathrm{V}}{\partial \mathrm{r}_{\mathrm{i}}}
$$

where $r_{i}$ represents the position vectors of each atom with respect to the origin coordinate, and $V$ is the potential energy function. In fact, any stable force can be determined through considering the negative gradient of the potential energy function. In molecular dynamics simulation, the movement of electrons is neglected and the potential energy of a system is defined as a function of the molecules' core position which is called a force field.

\section{Determination of system properties}

In the molecular approach, it is assumed that the macroscopic properties are obtained by considering the average statistical groups of molecular systems. To calculate macroscopic properties, it is necessary to produce a sample collection at a given temperature; moreover, the calculation of the free energy and thermodynamic properties is required for extending and developing molecular simulation techniques. In addition, molecular simulation can also determine atomic details, including structure and momentum. Since these details are limited to macroscopic properties, a method is needed for analyzing interactions on the basis of statistical mechanics. In order to model intermolecular interactions, the potential energy function is required for describing the geometry of molecules. Hence, the potential function must be selected prior to the simulation. For $N$ molecules, a potential function is shown as $\mathrm{V}\left(\mathrm{r}^{\mathrm{N}}\right)$, where $\mathrm{r}^{\mathrm{N}}$ represents a collection of vectors that show the position of each atom. In fact, the general configuration of the system is defined through determining these vectors.

In molecular dynamics simulation, the instantaneous value of a property $(A)$ such as the potential energy or any other properties can be considered as a function of the total points, i.e., $\mathrm{A}\left(\mathrm{r}^{\mathrm{N}}, \mathrm{p}^{\mathrm{N}}\right)$, which changes with the passage of time. In fact, the empirical macroscopic property $(A)$ is the time average of $\mathrm{A}\left(\mathrm{r}^{\mathrm{N}}, \mathrm{p}^{\mathrm{N}}\right)$ over a long period of time.

Molecular trajectories represent the state of a system as a function of time. The system usually reaches an equilibrium state after initial changes, and many macroscopic properties are determined by calculating the average values of these equilibrium trajectories. Upon integrating the equation of motion, the momentum of the atoms is obtained and molecular coordinates are calculated by repeating the integrations. After determining the integrating procedure, the trajectory of every molecule can be obtained and consequently the time average for a macroscopic property $\langle\mathrm{A}\rangle$ can be calculated, as shown by Eq. (35).

$$
\langle A\rangle=\lim _{t \rightarrow \infty} \frac{1}{t} \int_{t_{0}}^{t_{0}+t} A(\tau) d \tau
$$

Since molecules are constantly in motion and they collide with each other, their momentum changes continuously. Thus, the result obtained for a specific property at a given time step may be completely different from that obtained in the next time step. Indeed, the property of a system changes over time. Hence, it is necessary to consider the average system property.

Using mathematical equations, it is possible to study the properties of different materials in various phases, including gas, liquid, and solid, at a given molecular level. In so doing, the interactions between atoms and molecules are very significant and intermolecular force is one of the factors which determine the thermodynamic properties. Given the interactions between dissimilar molecules, as compared with pure substances, the above mentioned issue is of great importance in mixtures. Therefore, these intermolecular interactions are divided into bonded and non-bonded interactions. 


\section{Calculation of free energy}

Free energy is the most important thermodynamic parameter, which determines the main properties of materials. In fact, free energy is a statistical characteristic which determines the status of a system in a special state. In order to estimate the value of absolute free energy, the free energy difference between two interdependent states of a system must be calculated. In fact, this difference is attributed to the relative probability of a system remaining in one state against another one. The change in free energy of a system is calculated by the following equation:

$\Delta \mathrm{G}=\Delta \mathrm{H}-\mathrm{T} \Delta \mathrm{S}$

Typically, free energy is expressed as the Helmholtz free energy function $(A)$ or Gibbs free energy function $(G)$. For a system, the Helmholtz function is dependent on the number of particles, temperature, and volume $(N V T)$, while the Gibbs function is dependent on the number of particles, temperature, and pressure (NPT).

Free energy is calculated using two methods: the integral method and the perturbation method. These methods are dependent on the coupling parameter $(\lambda)$, which determines the status of the system; its value ranges from zero to one. In the integral method, the Hamiltonian is considered as a function of the coupling parameter and the difference in free energy.

$\Delta \mathrm{F}_{\mathrm{BA}}=\mathrm{F}(\mathrm{B})-\mathrm{F}(\mathrm{A})=\int_{\lambda_{\mathrm{A}}}^{\lambda_{\mathrm{B}}} \frac{\partial \mathrm{F}(\lambda)}{\partial \lambda} \mathrm{d} \lambda=\int_{\lambda_{\mathrm{A}}}^{\lambda_{\mathrm{B}}}\left\langle\frac{\partial \mathrm{H}(\lambda)}{\partial \lambda}\right\rangle_{\lambda} \mathrm{d} \lambda$

In Eq. (37), the relative free energy between the two states $(A$ and $B)$ is expressed as an integral of the Hamiltonian derivative within a range of $\lambda_{A}$ to $\lambda_{B}$.

In the perturbation method, the free energy is estimated based on the probability of the system remaining in each of the two positions $(A$ and $B$ ). In this method, the difference in free energy is calculated as follows:

$$
\Delta \mathrm{F}_{\mathrm{BA}}=-\mathrm{k}_{\mathrm{B}} \mathrm{T} \ln \left\langle\exp ^{-\left(\mathrm{H}\left(\lambda_{\mathrm{B}}\right)-\mathrm{H}\left(\lambda_{\mathrm{A}}\right)\right) / \mathrm{k}_{\mathrm{B}} \mathrm{T}}\right\rangle_{\lambda_{\mathrm{A}}}
$$

Using molecular dynamics simulation, it is possible to determine thermodynamic properties and study timedependent phenomena. Molecular dynamics simulation methods can be applied to both equilibrium and nonequilibrium thermodynamic phenomena. One of the main applications of this method in the field of equilibrium phenomena is the estimation of solubility and phase behavior in supercritical fluid systems. These results are of great significance for industrial applications.

\section{Solvation free energy and solubility}

Solvation free energy is an important input parameter for predicting solubility. Solvation free energy, $\Delta \mathrm{G}^{\text {solv }}$, is a significant parameter for the transfer of a solute molecule from a fixed position in the ideal gas into a fixed position in the solution (Ben-Naim, 2013). In experimental methods, the solvation free energy is estimated through measuring the concentration of a solute in two coexisting phases. Using molecular dynamics simulation methods, the solvation free energy is determined through switching on the interactions between a single-solute molecule and the rest of the solution in NPT or NVT ensembles (Garrido et al., 2009).

Based on thermodynamic relationships for mixtures, the fugacity of a solute at infinite dilution is defined by Eq. (39).

$$
\mathrm{f}_{2}=\mathrm{y}_{2} \rho \mathrm{k}_{\mathrm{B}} \operatorname{Texp}\left(\beta \Delta \mathrm{G}^{\text {solv }}\right)
$$

where $y_{2}$ is the mole fraction of a solute and $\rho$ is the density of pure solvent. In this equation, $\beta$ is $1 / \mathrm{k}_{\mathrm{B}} \mathrm{T}$ where $\mathrm{k}_{\mathrm{B}}$ and $T$ are Boltzmann's constant and absolute temperature, respectively.

Considering the thermodynamic of dilute solutions, the fugacity of a solute is obtained with Henry's constant which depends highly on the composition.

$\mathrm{f}_{2}=\mathrm{H}_{2} \mathrm{y}_{2}$

A comparison of Eqs. (39) and (40) yields the following expression for Henry's constant of a solute.

$$
\mathrm{H}_{2}=\rho \mathrm{k}_{\mathrm{B}} \mathrm{Texp}\left(\beta \Delta \mathrm{G}^{\mathrm{solv}}\right)
$$

The fugacity of pure solid can be determined using the following equation:

$$
\mathrm{f}_{2}^{\mathrm{s}}=\mathrm{P}_{2}^{\mathrm{sat}} \exp \left[\beta \mathrm{v}^{\mathrm{s}}\left(\mathrm{P}-\mathrm{P}_{2}^{\mathrm{sat}}\right)\right]
$$

where $\mathrm{P}_{2}^{\text {sat }}$ and $v^{\mathrm{s}}$ are the sublimation pressure and molar volume of the solute, respectively.

Based on the equilibrium criterion, the fugacity of a solute in both the solid and supercritical fluid phases must be identical. Hence, the mole fraction of a solute can be expressed by Eq. (43).

$$
\mathrm{y}_{2}=\frac{\mathrm{P}_{2}^{\text {sat }} \exp \left[\beta \mathrm{v}^{\mathrm{s}}\left(\mathrm{P}-\mathrm{P}_{2}^{\text {sat }}\right)\right]}{\rho \mathrm{k}_{\mathrm{B}} T \exp \left(\beta \Delta \mathrm{G}^{\text {solv }}\right)}
$$

Noroozi et al. (2016) investigated the precision of a molecular dynamics simulation method for predicting the solubility of two pharmaceutical solids, namely ibuprofen and acetaminophen in supercritical carbon dioxide. They applied three popular $\mathrm{CO}_{2}$ models 
Table 2. Comparison of simulated and experimental solubility of acetaminophen and ibuprofen in supercritical $\mathrm{CO}_{2}$ (Noroozi et al., 2016).

\begin{tabular}{cccccc}
\hline Solute & Density $\left(\mathbf{K m o l} / \mathbf{m}^{3}\right)$ & TraPPE & -EPM2 & Zhang & Exp \\
\hline & 14.30 & \multicolumn{2}{c}{ Mole fraction $\times 10^{6}$} \\
Acetaminophen & 16.61 & 0.53 & 0.29 & 0.16 & 0.37 \\
(T=313 K) & 18.50 & 1.24 & 0.61 & 0.36 & 0.65 \\
& 19.98 & 2.44 & 1.14 & 0.66 & 1.08 \\
\hline \multirow{7}{*}{ Ibuprofen } & 16.24 & 3.80 & 1.82 & 1.08 & 1.78 \\
(T=308 K) & 17.46 & 1.40 & 1.08 & 0.66 & 1.35 \\
& 18.81 & 2.07 & 1.59 & 1.04 & 2.13 \\
& 20.03 & 3.15 & 2.13 & 1.39 & 3.23 \\
\hline
\end{tabular}

(Zhang, EPM2, and TraPPE) to examine the influence of the solvent model on results. A comparison between their simulated results and experimental data is presented in Table (2). Based on the results obtained by Noroozi et al. (2016), molecular dynamics simulation has a good level of accuracy in predicting solubility in supercritical fluids, which makes it a powerful tool in this field.

In addition to determination of solubility, molecular dynamics simulation can be used for studying high-pressure phase behavior. Phase transitions in supercritical fluid systems are detected through changes in some properties of components such as the radial distribution function, enthalpy, and heat capacity (Seo et al., 2005; Skarmoutsos et al., 2005; Wang et al., 2016).

Many researchers have conducted various studies in the field of solubility (Cheng et al., 2012; Nayeem and Deep, 2010; Li et al., 2014; Yuan et al., 2010; Favero and Skaf, 2005; Noroozi et al., 2016). In addition, phase behavior was comprehensively studied by Eslami et al. (2009), Feng et al. (2014), and other researchers (Skarmoutsos et al., 2005; López-Rendón and Alejandre, 2008; Köddermann et al., 2011; Köster et al., 2012; Chaban, 2016; Wang et al., 2016).

\section{Monte Carlo simulation method}

The Monte Carlo method is used for all simulations which apply a stochastic procedure to generate a new configuration for a system. In Monte Carlo simulations, an initial configuration of particles in a system is determined and then, Monte Carlo movement is applied to change the configuration of the particles. These movements occur on the basis of the Metropolis criterion, which may be accepted or rejected. The exact value of a property can be obtained through considering these movements.

Compared with molecular dynamics simulation methods, Monte Carlo simulation is independent of time. In this method, a series of microscopic states are produced based on a given random law; hence, it is not necessary to solve Newton's equations of motion. Indeed, the Monte Carlo simulation method is a numerical technique for the equilibrium phenomena. Moreover, this method cannot be applied for dynamic properties.

The natural ensemble for a Monte Carlo simulation method is a canonical ensemble or NVT. Monte Carlo simulation methods are widely used for modeling vapor-liquid equilibrium and multiphase equilibrium, and studying solubility in supercritical fluids (Iwai et al., 1995; Errington et al., 1998; Iwai et al., 1998; Agrawal et al., 1999; Jorgensen and Duffy, 2000; Agrawal et al., 2001; Kamath and Potoff, 2006; Ferrando and Ungerer, 2007; Boulougouris et al., 2010; Bai and Siepmann, 2011; Stubbs, 2011; Zeng et al., 2014).

\section{CONCLUSIONS}

Given the importance of solubility in different areas such as chemical, pharmaceutical, and food industries, it has been the subject of intense research in recent decades. It is of utmost importance to obtain solubility data for various materials using experimental and theoretical methods, and select the optimal method.

In addition to high cost and time demands, a high level of precision and expertise in sampling is required for determining solubility via conventional experimental methods. As a result, many efforts have been made in this field to develop prediction models. Semiempirical models have a high level of accuracy because they rely on experimental data. Equations of state-based methods are less accurate, because some approximations are implemented which require various parameters estimated by different methods.

Nowadays, molecular simulation methods have a high potential to determine solubility and predict high-pressure phase behavior. Because of the utilization of significant physical models, molecular simulation methods have received much attention. In addition, these methods can be applied for mixtures without additional parameters. A reasonable level of consistency between molecular simulation results and experimental data proves the high level of accuracy in these methods. 
The primary goal of this study was to obtain a better insight toward previous studies on solubility in supercritical fluids and explain the significant parameters influencing this process.

\section{NOMENCLATURE}

$\begin{array}{ll}\mathrm{F} & \text { Degree of freedom } \\ \mathrm{NC} & \text { Number of components } \\ \mathrm{NP} & \text { Number of phases } \\ \mathrm{T} & \text { Temperature } \\ \mathrm{P} & \text { Pressure } \\ \rho & \text { Density } \\ \mathrm{f}_{\mathrm{i}} & \text { Fugacity of component } \mathrm{i} \\ \phi_{\mathrm{i}} & \text { Fugacity coefficient of component } \mathrm{i} \\ \mu_{\mathrm{i}} & \text { Potential function of component } \mathrm{i} \\ \mathrm{V} & \text { Molar volume } \\ \mathrm{X} & \text { Number of moles } \\ \mathrm{TPD} & \text { Tangent plane distance } \\ \gamma_{\mathrm{i}} & \text { Activity coefficient of component } \mathrm{i} \\ \delta & \text { Solubility parameter } \\ \mathrm{N} & \text { Number of particles } \\ \mathrm{V} & \text { Volume } \\ \mathrm{K} & \text { Kinetic energy } \\ \mathrm{U} & \text { Potential energy } \\ \mathrm{H} & \text { Enthalpy } \\ \mathrm{S} & \text { Entropy } \\ \mathrm{G} & \text { Gibbs free energy } \\ \mathrm{F}_{\mathrm{i}} & \text { Force } \\ \mathrm{m}_{\mathrm{i}} & \text { Particle mass } \\ \mathrm{a}_{\mathrm{i}} & \text { Particle acceleration } \\ \mathrm{p} & \text { Momentum of molecule } \\ \mathrm{q} & \text { Coordinate of molecule } \\ \mathrm{H}(\mathrm{p}, \mathrm{q}) & \text { Hamiltonian } \\ \mathrm{V}(\mathrm{r}) & \text { Potential function } \\ \lambda & \text { Coupling parameter } \\ \mathrm{k}_{\mathrm{B}} & \text { Boltzmann's constant } \\ \Delta \mathrm{G}^{\text {solv }} & \text { Solvation free energy } \\ & \end{array}$

\section{REFERENCES}

Adachi, Y., Lu, B. C.-Y. Supercritical fluid extraction with carbon dioxide and ethylene. Fluid Phase Equilibria, 14, 147-156 (1983). https://doi. org/10.1016/0378-3812(83)80120-4

Adrian, T., Wendland, M., Hasse, H., Maurer, G. Highpressure multiphase behaviour of ternary systems carbon dioxide-water-polar solvent: review and modeling with the Peng-Robinson equation of state. The Journal of Supercritical Fluids, 12, 185-221 (1998). https://doi.org/10.1016/S08968446(98)00087-4

Agrawal, P. M., Rice, B. M., Sorescu, D. C., Thompson, D. L. Models for predicting solubilities of 2,4,6-trinitrotoluene (TNT) and 1,3,5-trinitro1,3,5-s-triazine $(\mathrm{RDX})$ in supercritical $\mathrm{CO}_{2}$ : isothermal-isobaric Monte Carlo simulations. Fluid Phase Equilibria, 187, 139-153 (2001). https://doi. org/10.1016/S0378-3812(01)00533-7

Agrawal, P. M., Sorescu, D. C., Rice, B. M., Thompson, D. L. A model for predicting the solubility of 1,3,5-trinitro-1,3,5-s-triazine (RDX) in supercritical $\mathrm{CO}_{2}$ : isothermal-isobaric Monte Carlo simulations. Fluid Phase Equilibria, 155, 177-191 (1999). https://doi.org/10.1016/S03783812(98)00471-3

Aim, K., Fermeglia, M. Solubility of Solids and Liquids in Supercritical Fluids. The Experimental Determination of Solubilities, Volume 6, 491-555 (2002). https://doi.org/10.1002/0470867833.ch13

Akbari, Z., Amanlou, M., Karimi-Sabet, J., Golestani, A., Niasar, M. S. Characterization of carbamazepineloaded solid lipid nanoparticles prepared by rapid expansion of supercritical solution. Tropical Journal of Pharmaceutical Research, 13, 19551961 (2014). https://doi.org/10.4314/tjpr.v13i12.1

Akbari, Z., Amanlou, M., Karimi-Sabet, J., Golestani, A., Niassar, M. S. Preparation and characterization of solid lipid nanoparticles through rapid expansion of supercritical solution. International Journal of Pharmaceutical Sciences and Research, 5, 1693 (2014).

Akbari, Z., Amanlou, M., Karimi-Sabet, J., Golestani, A., Niassar, M. S. Production of Ibuprofen-Loaded Solid Lipid Nanoparticles Using Rapid Expansion of Supercritical Solution. Journal of Nano Research, 31, 15-29 (2015). https://doi.org/10.4028/www. scientific.net/JNanoR.31.15

Anvari, M. H., Pazuki, G. A study on the predictive capability of the SAFT-VR equation of state for solubility of solids in supercritical $\mathrm{CO}_{2}$. The Journal of Supercritical Fluids, 90, 73-83 (2014). https:// doi.org/10.1016/j.supflu.2014.03.005

Aschenbrenner, O., Kemper, S., Dahmen, N., Schaber, K., Dinjus, E. Solubility of $\beta$-diketonates, cyclopentadienyls, and cyclooctadiene complexes with various metals in supercritical carbon dioxide. The Journal of Supercritical Fluids, 41, 179-186 (2007). https://doi.org/10.1016/j. supflu.2006.10.011

Bai, P., Siepmann, J. I. Gibbs ensemble Monte Carlo simulations for the liquid-liquid phase equilibria of dipropylene glycol dimethyl ether and water: A preliminary report. Fluid Phase Equilibria, 310, 11-18 (2011). https://doi.org/10.1016/j. fluid.2011.06.003

Bartle, K., Clifford, A., Jafar, S., Shilstone, G. Solubilities of solids and liquids of low volatility in supercritical carbon dioxide. Journal of Physical and Chemical Reference Data, 20, 713-756 (1991). https://doi.org/10.1063/1.555893 
Beckman, E. J. Supercritical and near-critical $\mathrm{CO}_{2}$ in green chemical synthesis and processing. The Journal of Supercritical Fluids, 28, 121-191 (2004). https://doi.org/10.1016/S0896-8446(03)00029-9

Behjati Rad, H., Karimi Sabet, J., Varaminian, F. Effect of stearic acid as a co-solvent on the solubility enhancement of aspirin in supercritical $\mathrm{CO}_{2}$, Journal of Chemical Engineering \& Technology, 42, 1259-1267 (2019). https://doi.org/10.1002/ ceat.201900043

Ben-Naim, A. Solvation thermodynamics, Springer Science \& Business Media (2013). https://doi. org/10.1142/9031

Bitencourt, R. G., Cabral, F. A., Meirelles, A. J. Ferulic acid solubility in supercritical carbon dioxide, ethanol and water mixtures. The Journal of Chemical Thermodynamics, 103, 285-291 (2016). https://doi.org/10.1016/j.jct.2016.08.025

Bittrich, H.-J., Lempe, D., Reinhardt, K., Wüstling, J.-U. Liquid-liquid equilibria in binary mixtures of N-methyl- $\alpha$-pyrrolidone and saturated hydrocarbons. Part II. Fluid Phase Equilibria, 126, 115-125 (1996). https://doi.org/10.1016/S03783812(96)03135-4

Błaszczyński, T., Ślosarczyk, A., Morawski, M. Synthesis of silica aerogel by supercritical drying method. Procedia Engineering, 57, 200-206 (2013). https://doi.org/10.1016/j.proeng.2013.04.028

Borg, P., Jaubert, J.-N., Denet, F. Solubility of $\alpha$-tetralol in pure carbon dioxide and in a mixed solvent formed by ethanol and carbon dioxide. Fluid Phase Equilibria, 191, 59-69 (2001). https:// doi.org/10.1016/S0378-3812(01)00612-4

Boulougouris, G. C., Peristeras, L. D., Economou, I. G., Theodorou, D. N. Predicting fluid phase equilibrium via histogram reweighting with Gibbs ensemble Monte Carlo simulations. The Journal of Supercritical Fluids, 55, 503-509 (2010). https:// doi.org/10.1016/j.supflu.2010.09.024

Brandalize, M. V., Gaschi, P. S., Mafra, M. R., Ramos, L. P., Corazza, M. L. High-pressure phase equilibrium measurements and thermodynamic modeling for the systems involving $\mathrm{CO}_{2}$, ethyl esters (oleate, stearate, palmitate) and acetone. Chemical Engineering Research and Design, 92, 2814-2825 (2014). https://doi.org/10.1016/j. cherd.2014.04.028

Brunner, G., Supercritical fluids: technology and application to food processing. Journal of Food Engineering, 67, 21-33 (2005). https://doi. org/10.1016/j.jfoodeng.2004.05.060

Cabrera, A. L., Toledo, A. R., Valle, J. M. del, Juan, C. Measuring and validation for isothermal solubility data of solid 2-(3,4-Dimethoxyphenyl)5,6,7,8-tetramethoxychromen-4-one (nobiletin) in supercritical carbon dioxide. The Journal of
Chemical Thermodynamics, 91, 378-383 (2015). https://doi.org/10.1016/j.jct.2015.08.018

Cansell, F., Aymonier, C. Design of functional nanostructured materials using supercritical fluids. The Journal of Supercritical Fluids, 47, 508-516 (2009). https://doi.org/10.1016/j.supflu.2008.10.002

Ch, R., Madras, G. An association model for the solubilities of pharmaceuticals in supercritical carbon dioxide. Thermochimica Acta, 507, 99-105 (2010). https://doi.org/10.1016/j.tca.2010.05.006

Chaban, V. V. Vapor-liquid equilibria in the binary mixtures of N-butylpyridinium hexafluorophophate and bis (trifluoromethanesulfonyl) imide ionic liquids with acetone: Molecular dynamics simulations. Fluid Phase Equilibria, 419, 75-83 (2016). https://doi.org/10.1016/j.fluid.2016.03.015

Chen, C.-T., Lee, C.-A., Tang, M., Chen, Y.-P. Experimental investigation for the solubility and micronization of pyridin-4-amine in supercritical carbon dioxide. Journal of $\mathrm{CO}_{2}$ Utilization, 18, 173-180 (2017). https://doi.org/10.1016/j.jcou.2017.01.020

Cheng, J.-S., Tang, M., Chen, Y.-P. Correlation of solid solubility for biological compounds in supercritical carbon dioxide: comparative study using solution model and other approaches. Fluid Phase Equilibria, 194, 483-491 (2002). https://doi. org/10.1016/S0378-3812(01)00657-4

Cheng, T., Li, F., Dai, J., Sun, H. Prediction of the mutual solubility of water and dipropylene glycol dimethyl ether using molecular dynamics simulation. Fluid Phase Equilibria, 314, 1-6 (2012). https://doi.org/10.1016/j.fluid.2011.10.013

Chim, R., Marceneiro, S., Braga, M. E., Dias, A. M., Sousa, H. C. de. Solubility of norfloxacin and ofloxacin in supercritical carbon dioxide. Fluid Phase Equilibria, 331, 6-11 (2012). https://doi. org/10.1016/j.fluid.2012.06.023

Chobanov, K., Tuma, D., Maurer, G. High-pressure phase behavior of ternary systems (carbon dioxide+ alkanol+ hydrophobic ionic liquid). Fluid Phase Equilibria, 294, 54-66 (2010). https://doi. org/10.1016/j.fluid.2010.02.015

Chrastil, J. Solubility of solids and liquids in supercritical gases. The Journal of Physical Chemistry, 86, 3016-3021 (1982). https://doi. org $/ 10.1021 / \mathrm{j} 100212 \mathrm{a} 041$

Christov, M., Dohrn, R. High-pressure fluid phase equilibria: experimental methods and systems investigated (1994-1999). Fluid Phase Equilibria, 202, 153-218 (2002). https://doi.org/10.1016/ S0378-3812(02)00096-1

Coimbra, P., Duarte, C., Sousa, H. de. Cubic equationof-state correlation of the solubility of some antiinflammatory drugs in supercritical carbon dioxide. Fluid Phase Equilibria, 239, 188-199 (2006). https://doi.org/10.1016/j.fluid.2005.11.028 
Cortesi, A., Kikic, I., Alessi, P., Turtoi, G., Garnier, S. Effect of chemical structure on the solubility of antioxidants in supercritical carbon dioxide: experimental data and correlation. The Journal of Supercritical Fluids, 14, 139-144 (1999). https:// doi.org/10.1016/S0896-8446(98)00119-3

Crampon, C., Charbit, G., Neau, E. High-pressure apparatus for phase equilibria studies: solubility of fatty acid esters in supercritical $\mathrm{CO}_{2}$. The Journal of Supercritical Fluids, 16, 11-20 (1999). https://doi. org/10.1016/S0896-8446(99)00021-2

Danlami, J. M., Zaini, M. A. A., Arsad, A., Yunus, M. A. C. Solubility assessment of castor (Ricinus communis L) oil in supercritical $\mathrm{CO}_{2}$ at different temperatures and pressures under dynamic conditions. Industrial Crops and Products, 76, 34-40 (2015). https://doi.org/10.1016/j. indcrop.2015.06.010

De Zordi, N., Kikic, I., Moneghini, M., Solinas, D. Solubility of pharmaceutical compounds in supercritical carbon dioxide. The Journal of Supercritical Fluids, 66, 16-22 (2012). https://doi. org/10.1016/j.supflu.2011.09.018

Deiters, U. K., Kraska, T. High-Pressure Fluid Phase Equilibria: Phenomenology and Computation, Elsevier, (2012).

Del Valle, J. M., Aguilera, J. M. An improved equation for predicting the solubility of vegetable oils in supercritical carbon dioxide. Industrial \& Engineering Chemistry Research, 27, 1551-1553 (1988). https://doi.org/10.1021/ie00080a036

Deuflhard, P., Hermans, J., Leimkuhler, B., Mark, A. E., Reich, S., Skeel, R. D. Computational Molecular Dynamics: Challenges, Methods, Ideas: Proceeding of the 2nd International Symposium on Algorithms for Macromolecular Modelling, Berlin, May 21-24, 1997, Springer Science \& Business Media, (2012).

Dohrn, R., Brunner, G. High-pressure fluid-phase equilibria: experimental methods and systems investigated (1988-1993). Fluid Phase Equilibria, 106, 213-282 (1995). https://doi.org/10.1016/03783812(95)02703-H

Dohrn, R., Peper, S., Fonseca, J. M. High-pressure fluid-phase equilibria: experimental methods and systems investigated (2000-2004). Fluid Phase Equilibria, 288, 1-54 (2010). https://doi. org/10.1016/j.fluid.2009.08.008

Duba, K. S., Fiori, L. Solubility of grape seed oil in supercritical $\mathrm{CO}_{2}$ : Experiments and modeling. The Journal of Chemical Thermodynamics, 100, 44-52 (2016). https://doi.org/10.1016/j.jct.2016.04.010

Errington, J., Kiyohara, K., Gubbins, K., Panagiotopoulos, A. Monte Carlo simulation of high-pressure phase equilibria in aqueous systems. Fluid Phase Equilibria, 150, 33-40 (1998). https:// doi.org/10.1016/S0378-3812(98)00273-8
Eslami, H., Dargahi, A., Behnejad, H. Molecular dynamics simulation of liquid-vapor phase equilibria in polar fluids. Chemical Physics Letters, 473, 66-71 (2009). https://doi.org/10.1016/j. cplett.2009.03.040

Esmaeilzadeh, F., Asadi, H., Lashkarbolooki, M. Calculation of the solid solubilities in supercritical carbon dioxide using a new $\mathrm{G}^{\mathrm{ex}}$ mixing rule. The Journal of Supercritical Fluids, 51, 148-158 (2009). https://doi.org/10.1016/j.supflu.2009.08.005

Espinosa, S., Fornari, T., Bottini, S. B., Brignole, E. A. Phase equilibria in mixtures of fatty oils and derivatives with near critical fluids using the GCEOS model. The Journal of Supercritical Fluids, 23, 91-102 (2002). https://doi.org/10.1016/S08968446(02)00025-6

Fabre, C. E., Condoret, J. S., Marty, A. Extractive fermentation of aroma with supercritical $\mathrm{CO}_{2}$, Biotechnol Bioeng, 64, 392-400 (1999). https://doi.org/10.1002/(SICI)10970290 ( 19990820$) 64: 4 \% 3$ C 392:: A ID BIT2\%3E3.0.CO;2-G

Fages, J., Lochard, H., Letourneau, J.-J., Sauceau, M., Rodier, E. Particle generation for pharmaceutical applications using supercritical fluid technology. Powder Technology, 141, 219-226 (2004). https:// doi.org/10.1016/j.powtec.2004.02.007

Fattahi, A., Karimi-Sabet, J., Keshavarz, A., Golzary, A., Rafiee-Tehrani, M., Dorkoosh, F. Preparation and characterization of simvastatin nanoparticles using rapid expansion of supercritical solution (RESS) with trifluoromethane. The Journal of Supercritical Fluids, 107, 469-478 (2016). https:// doi.org/10.1016/j.supflu.2015.05.013

Favero, F. W., Skaf, M. Solvation of purine alkaloids in supercritical $\mathrm{CO}_{2}$ by molecular dynamics simulations. The Journal of Supercritical Fluids, 34, 237-241 (2005). https://doi.org/10.1016/j. supflu.2004.11.020

Feng, Y., Tang, W., Huang, Y., Xiong, Y., Chen, L., Liu, Y., Li, Y. (Solid+ liquid) phase equilibria of tetraphenyl piperazine-1,4-diyldiphosphonate in pure solvents. The Journal of Chemical Thermodynamics, 78, 143-151 (2014). https://doi. org/10.1016/j.jct.2014.06.021

Fernández-Ronco, M., Cismondi, M., Gracia, I., Lucas, A. de, Rodríguez, J. High-pressure phase equilibria of binary and ternary mixtures of carbon dioxide, triglycerides and free fatty acids: measurement and modeling with the GC-EOS. Fluid Phase Equilibria, 295, 1-8 (2010). https://doi. org/10.1016/j.fluid.2010.03.016

Ferrando, N., Ungerer, P. Hydrogen/hydrocarbon phase equilibrium modelling with a cubic equation of state and a Monte Carlo method. Fluid Phase Equilibria, 254, 211-223 (2007). https://doi. org/10.1016/j.fluid.2007.03.016 
Ferri, A., Banchero, M., Manna, L., Sicardi, S. An experimental technique for measuring high solubilities of dyes in supercritical carbon dioxide. The Journal of Supercritical Fluids, 30, 41-49 (2004). https://doi.org/10.1016/S08968446(03)00114-1

Fonseca, J. M., Dohrn, R., Peper, S. High-pressure fluid-phase equilibria: experimental methods and systems investigated (2005-2008). Fluid Phase Equilibria, 300, 1-69 (2011). https://doi. org/10.1016/j.fluid.2010.09.017

Fornari, R. E., Alessi, P., Kikic, I. High pressure fluid phase equilibria: experimental methods and systems investigated (1978-1987). Fluid Phase Equilibria, 57, 1-33 (1990). https://doi.org/10.1016/03783812(90)80010-9

Freitag, J., Tuma, D., Ulanova, T. V., Maurer, G. Highpressure multiphase behavior of the ternary systems (ethene+water+1-propanol) and (ethene+water+2propanol): Part II: Modeling. The Journal of Supercritical Fluids, 39, 174-186 (2006). https:// doi.org/10.1016/j.supflu.2006.03.001

Fu, D., Sun, X., Qiu, Y., Jiang, X., Zhao, S. Highpressure phase behavior of the ternary system $\mathrm{CO}_{2}+$ ionic liquid $[\mathrm{bmim}]\left[\mathrm{PF}_{6}\right]+$ naphthalene. Fluid Phase Equilibria, 251, 114-120 (2007). https://doi. org/10.1016/j.fluid.2006.11.010

Galia, A., Argentino, A., Scialdone, O., Filardo, G. A new simple static method for the determination of solubilities of condensed compounds in supercritical fluids. The Journal of Supercritical Fluids, 24, 7-17 (2002). https://doi.org/10.1016/ S0896-8446(02)00009-8

Garrido, N. M., Queimada, A. J., Jorge, M., Macedo, E. A., Economou, I. G. 1-Octanol/water partition coefficients ofn-alkanes from molecular simulations of absolute solvation free energies. Journal of Chemical Theory and Computation, 5, 2436-2446 (2009). https://doi.org/10.1021/ct900214y

Ghaziaskar, H. S., Kaboudvand, M. Solubility of trioctylamine in supercritical carbon dioxide. The Journal of Supercritical Fluids, 44, 148-154 (2008). https://doi.org/10.1016/j.supflu.2007.10.006

Gong, X.-Y., Cao, X.-J. Measurement and correlation of solubility of artemisinin in supercritical carbon dioxide. Fluid Phase Equilibria, 284, 26-30 (2009). https://doi.org/10.1016/j.fluid.2009.05.018

Gordillo, M., Blanco, M., Molero, A., De La Ossa, E. M, Solubility of the antibiotic penicillin $G$ in supercritical carbon dioxide. The Journal of Supercritical Fluids, 15, 183-190 (1999). https:// doi.org/10.1016/S0896-8446(99)00008-X

Gupta, A. K., Bishnoi, P. R., Kalogerakis, N. A method for the simultaneous phase equilibria and stability calculations for multiphase reacting and non-reacting systems. Fluid Phase Equilibria, 63, 65-89 (1991). https://doi.org/10.1016/03783812(91)80021-M

Gutiérrez, J. E., Bejarano, A., Juan, C. Measurement and modeling of high-pressure (vapour+liquid) equilibria of $\left(\mathrm{CO}_{2}+\right.$ alcohol $)$ binary systems. The Journal of Chemical Thermodynamics, 42, 591-596 (2010). https://doi.org/10.1016/j.jct.2009.11.015

Hadi, A., Karimi-Sabet, J., Moosavian, S. M. A., Ghorbanian, S. Optimization of graphene production by exfoliation of graphite in supercritical ethanol: A response surface methodology approach. The Journal of Supercritical Fluids, 107, 92-105 (2016). https://doi.org/10.1016/j.supflu.2015.08.022

Harvey, A. H. On the suitability of the virial equation for modeling the solubility of solids in supercritical fluids. Fluid Phase Equilibria, 130, 87-100 (1997). https://doi.org/10.1016/S0378-3812(96)03228-1

Henderson, N., Barufatti, N. E., Sacco, W. F. The Least Dot Products method: A new numerical paradigm for phase stability analysis of thermodynamic mixtures. Chemical Engineering Science, 66, 5684-5702 (2011). https://doi.org/10.1016/j. ces.2011.08.004

Hezave, A. Z., Shahnazar, S., Rajaei, H., Lashkarbolooki, M, Esmaeilzadeh, F. Solubility of spironolactone in supercritical carbon dioxide: Experimental and modeling approaches. Fluid Phase Equilibria, 355, 130-134 (2013). https://doi. org/10.1016/j.fluid.2013.07.003

Hojjati, M., Yamini, Y., Khajeh, M., Vatanara, A. Solubility of some statin drugs in supercritical carbon dioxide and representing the solute solubility data with several density-based correlations. The Journal of Supercritical Fluids, 41, 187-194 (2007). https://doi.org/10.1016/j.supflu.2006.10.006

Hosseini, M. H., Alizadeh, N., Khanchi, A. R. Solubility analysis of clozapine and lamotrigine in supercritical carbon dioxide using static system. The Journal of Supercritical Fluids, 52, 30-35 (2010). https://doi.org/10.1016/j.supflu.2009.11.006

Hou, Y., Tian, S., Lü, C., Sun, N., Wu, W. High pressure phase equilibrium of carbon dioxide and benzaldehyde binary system. Fluid Phase Equilibria, 325, 11-14 (2012). https://doi. org/10.1016/j.fluid.2012.04.007

Huang, C.-Y., Lee, L.-S., Su, C.-S. Correlation of solid solubilities of pharmaceutical compounds in supercritical carbon dioxide with solution model approach. Journal of the Taiwan Institute of Chemical Engineers, 44, 349-358 (2013). https:// doi.org/10.1016/j.jtice.2012.12.004

Huang, Z.,. Chiew, Y., Lu, W.-D., Kawi, S. Solubility of aspirin in supercritical carbon dioxide/alcohol mixtures. Fluid Phase Equilibria, 237, 9-15 (2005). https://doi.org/10.1016/j.fluid.2005.08.004 
Huang, Z., Lu, W. D., Kawi, S., Chiew, Y. C. Solubility of aspirin in supercritical carbon dioxide with and without acetone. Journal of Chemical \& Engineering Data, 49, 1323-1327 (2004). https:// doi.org/10.1021/je0499465

Ikushima, Y. Supercritical fluids: an interesting medium for chemical and biochemical processes. Advances in Colloid and Interface Science, 71, 259-280 (1997). https://doi.org/10.1016/S0001-8686(97)00021-3

Iwai, Y., Uchida, H., Arai, Y., Mori, Y. Monte Carlo simulation of solubilities of naphthalene, phenanthrene, and anthracene in supercritical fluids. Fluid Phase Equilibria, 144, 233-244 (1998). https://doi.org/10.1016/S0378-3812(97)00262-8

Iwai, Y., Uchida, H., Koga, Y., Mori, Y., Arai, Y. Monte Carlo calculation of solubilities of aromatic compounds in supercritical carbon dioxide. Fluid Phase Equilibria, 111, 1-13 (1995). https://doi. org/10.1016/0378-3812(95)02770-F

Iwai, Y., Uno, M., Nagano, H., Arai, Y. Measurement of solubilities of palmitic acid in supercritical carbon dioxide and entrainer effect of water by FTIR spectroscopy. The Journal of Supercritical Fluids, 28, 193-200 (2004). https://doi.org/10.1016/ S0896-8446(03)00013-5

Jessop, P. G., Leitner, W. Chemical synthesis using supercritical fluids, John Wiley \& Sons, (2008).

Jha, S. K., Madras, G. Modeling the solubilities of high molecular weight $n$-alkanes in supercritical carbon dioxide. Fluid Phase Equilibria, 225, 59-62 (2004). https://doi.org/10.1016/j.fluid.2004.07.006

Jianzhong, Y., Xianzhen, Z., Qinqin, X., Chuanjie, Z., Aiqin, W. Supercritical fluids deposition techniques for the formation of nanocomposites. Prog Chem, 21, 606-614 (2009).

Jin, J., Wang, Y., Liu, H., Zhang, Z. Determination and calculation of solubility of bisphenol $\mathrm{A}$ in supercritical carbon dioxide. Chemical Engineering Research and Design, 91, 158-164 (2013). https:// doi.org/10.1016/j.cherd.2012.06.013

Jin, J., Wang, Y., Wu, H., Li, J., Zhang, Z. Equilibrium solubilities of ammonium benzoate, benzamide and their mixture in supercritical carbon dioxide. Fluid Phase Equilibria, 334, 152-156 (2012). https://doi. org/10.1016/j.fluid.2012.05.031

Johnston, K. P., Penninger, J. M. Supercritical fluid science and technology, ACS Publications, (1989). https://doi.org/10.1021/bk-1989-0406

Jorgensen, W. L., Duffy, E. M. Prediction of drug solubility from Monte Carlo simulations. Bioorganic \& Medicinal Chemistry Letters, 10, 1155-1158 (2000). https://doi.org/10.1016/S0960$894 X(00) 00172-4$

Jouyban, A., Chan, H.-K., Foster, N. R. Mathematical representation of solute solubility in supercritical carbon dioxide using empirical expressions. The
Journal of Supercritical Fluids, 24, 19-35 (2002). https://doi.org/10.1016/S0896-8446(02)00015-3

Kamath, G., Potoff, J. J., Monte Carlo predictions for the phase behavior of $\mathrm{H}_{2} \mathrm{~S}+\mathrm{n}$-alkane, $\mathrm{H}_{2} \mathrm{~S}+\mathrm{CO}_{2}$, $\mathrm{CO}_{2}+\mathrm{CH}_{4}$ and $\mathrm{H}_{2} \mathrm{~S}+\mathrm{CO}_{2}+\mathrm{CH}_{4}$ mixtures. Fluid Phase Equilibria, 246, 71-78 (2006). https://doi. org/10.1016/j.fluid.2006.05.011

Keshavarz, A., Karimi-Sabet, J., Fattahi, A., Golzary, A., Rafiee-Tehrani, M., Dorkoosh, F. Preparation and characterization of raloxifene nanoparticles using rapid expansion of supercritical solution (RESS). The Journal of Supercritical Fluids, 63, 169-179 (2012). https://doi.org/10.1016/j.supflu.2011.12.005

Keshtkari, S., Haghbakhsh, R., Raeissi, S., Florusse, L., Peters, C. J. Vapor-liquid equilibria of isopropyl alcohol+ propylene at high pressures: experimental measurement and modeling with the CPA EoS. The Journal of Supercritical Fluids, 84, 182-189 (2013). https://doi.org/10.1016/j.supflu.2013.09.016

Khamda, M., Hosseini, M. H., Rezaee, M. Measurement and correlation solubility of cefixime trihydrate and oxymetholone in supercritical carbon dioxide $\left(\mathrm{CO}_{2}\right)$. The Journal of Supercritical Fluids, 73, 130-137 (2013). https://doi.org/10.1016/j. supflu.2012.09.006

Khayyat, Y., Kashkouli, S. M., Esmaeilzadeh, F. Solubility of fluvoxamine maleate in supercritical carbon dioxide. Fluid Phase Equilibria, 399, 98-104 (2015). https://doi.org/10.1016/j.fluid.2015.04.030

Knez, Z., Weidner, E. Particles formation and particle design using supercritical fluids. Current Opinion in Solid State and Materials Science, 7, 353-361 (2003). https://doi.org/10.1016/j. cossms.2003.11.002

Kodama, D., Miyazaki, J., Kato, M, Sako, T. High pressure phase equilibrium for ethylene+ 1-propanol system at $283.65 \mathrm{~K}$. Fluid Phase Equilibria, 219, 19-23 (2004). https://doi.org/10.1016/j. fluid.2004.01.010

Köddermann, T., Kirschner, K. N., Vrabec, J., Hülsmann, M., Reith, D. Liquid-liquid equilibria of dipropylene glycol dimethyl ether and water by molecular dynamics. Fluid Phase Equilibria, 310, 25-31 (2011). https://doi.org/10.1016/j.fluid.2011.07.015

Köster, A., Nandi, P., Windmann, T., Ramjugernath, D., Vrabec, J. Vapor-liquid equilibria of ethylene $\left(\mathrm{C}_{2} \mathrm{H}_{4}\right)+$ decafluorobutane $\left(\mathrm{C}_{4} \mathrm{~F}_{10}\right)$ at $268-298 \mathrm{~K}$ from experiment, molecular simulation and the PengRobinson equation of state. Fluid Phase Equilibria, 336, 104-112 (2012). https://doi.org/10.1016/j. fluid.2012.08.023

Kostrzewa, D., Dobrzyńska-Inger, A., Rój, E. Experimental data on xanthohumol solubility in supercritical carbon dioxide. Fluid Phase Equilibria, 360, 445-450 (2013). https://doi.org/10.1016/j. fluid.2013.10.001 
Kouakou, A., Ferreira, M., Schwarz, C. Phase equilibria of 3-methylstyrene, 4-methylstyrene, alpha-methylstyrene and a methylstyrene mixture in supercritical $\mathrm{CO}_{2}$. The Journal of Supercritical Fluids, 113, 198-206 (2016). https://doi. org/10.1016/j.supflu.2016.03.012

Kumar, S. K., Johnston, K. P. Modelling the solubility of solids in supercritical fluids with density as the independent variable. The Journal of Supercritical Fluids, 1, 15-22 (1988). https://doi. org/10.1016/0896-8446(88)90005-8

Kurnik, R. T., Reid, R. C. Solubility of solid mixtures in supercritical fluids. Fluid Phase Equilibria, 8, 93-105 (1982). https://doi.org/10.1016/03783812(82)80008-3

Lazzaroni, M. J., Bush, D., Eckert, C. A., Gläser, R. High-pressure vapor-liquid equilibria of argon+ carbon dioxide+ 2-propanol. The Journal of Supercritical Fluids, 37, 135-141 (2006). https:// doi.org/10.1016/j.supflu.2005.10.002

Lazzaroni, M. J., Bush, D., Jones, R., Hallett, J. P., Liotta, C. L., Eckert, C. A. High-pressure phase equilibria of some carbon dioxide-organic-water systems. Fluid Phase Equilibria, 224, 143-154 (2004). https://doi.org/10.1016/j.fluid.2004.06.061

Lemert, R. M., Johnston, K. P. Solid-liquid-gas equilibria in multicomponent supercritical fluid systems. Fluid Phase Equilibria, 45, 265-286(1989). https://doi.org/10.1016/0378-3812(89)80262-6

Li, B., Guo, W., Song, W., Ramsey, E. D. Interfacing supercritical fluid solubility apparatus with supercritical fluid chromatography operated with and without on-line post-column derivatization: Determining the solubility of caffeine and monensin in supercritical carbon dioxide. The Journal of Supercritical Fluids, 115, 17-25 (2016). https://doi. org/10.1016/j.supflu.2016.04.008

Li, J.-L., Jin, J.-S., Zhang, Pei, X.-M., Equilibrium solubilities of a p-toluenesulfonamide and sulfanilamide mixture in supercritical carbon dioxide with and without ethanol. The Journal of Supercritical Fluids, 52, 11-17 (2010). https://doi. org/10.1016/j.supflu.2009.11.011

Li, Q., Liu, C., Zhang, Z., Prediction of Solubility of Sulfur in Hydrogen Sulfide Based on Molecular Dynamics Simulation. Asian Journal of Chemistry, 26, 1041 (2014). https://doi.org/10.14233/ajchem.2014.15843

Li, Q., Zhang, Z., Zhong, C., Liu, Y., Zhou, Q. Solubility of solid solutes in supercritical carbon dioxide with and without cosolvents. Fluid Phase Equilibria, 207, 183-192 (2003). https://doi. org/10.1016/S0378-3812(03)00022-0

Li, Y., Tang, Z., Jin, J., Zhang, Z. Binary and ternary solubility of amino-and nitro-benzoic acids in supercritical carbon dioxide. Fluid Phase Equilibria, 344, 71-78 (2013). https://doi.org/10.1016/j. fluid.2013.01.021
Liao, S., Hou, Y., Li, S., Chen, X., Wu, W. Highpressure phase equilibria for the binary system carbon dioxide + benzyl alcohol. The Journal of Supercritical Fluids, 55, 32-36 (2010). https://doi. org/10.1016/j.supflu.2010.08.014

Liu, G.-T., Nagahama, K. Solubility of organic solid mixture in supercritical fluids. The Journal of Supercritical Fluids, 9, 152-160 (1996). https://doi. org/10.1016/S0896-8446(96)90026-1

López-Rendón, R., Alejandre, J. Molecular Dynamics Simulations of the Solubility of $\mathrm{H}_{2} \mathrm{~S}$ and $\mathrm{CO}_{2}$ in Water. Journal of the Mexican Chemical Society, 52, 88-92 (2008).

Lucien, F. P., Foster, N. R. Solubilities of solid mixtures in supercritical carbon dioxide: a review. The Journal of Supercritical Fluids, 17, 111-134 (2000). https://doi.org/10.1016/S0896-8446(99)00048-0

Lupis, C., Gaye, H. Metallurgical Chemistry. Proceedings of a Symposium held at Brunel University and the National Physical Laboratory (1971).

McHardy, J., Sawan, S. P. Supercritical fluid cleaning: fundamentals, technology and applications. Westwood. Noyes Publications (1998).

Machida, H., Matsumura, K., Horizoe, H. High pressure vapor-liquid equilibria measurements and modeling of butane/ethanol system and isobutane/ethanol system. Fluid Phase Equilibria, 375, 176-180 (2014). https://doi.org/10.1016/j.fluid.2014.05.018

Madras, G., Kulkarni, C., Modak, J. Modeling the solubilities of fatty acids in supercritical carbon dioxide. Fluid Phase Equilibria, 209, 207-213 (2003). https://doi.org/10.1016/S03783812(03)00148-1

Mahadik, D., Lee, Y. K., Chavan, N., Mahadik, S., Park, H.-H. Monolithic and shrinkagefree hydrophobic silica aerogels via new rapid supercritical extraction process. The Journal of Supercritical Fluids, 107, 84-91 (2016). https://doi. org/10.1016/j.supflu.2015.08.020

Masoodiyeh, F., Karimi-Sabet, J., Khanchi, A., Mozdianfard, M. Zirconia nanoparticle synthesis in sub and supercritical water-particle morphology and chemical equilibria. Powder Technology, 269, 461-469 (2015). https://doi.org/10.1016/j. powtec.2014.09.043

Masoodiyeh, F., Mozdianfard, M., Karimi-Sabet, J. Solubility estimation of inorganic salts in supercritical water. The Journal of Chemical Thermodynamics, 78, 260-268 (2014). https://doi. org/10.1016/j.jct.2014.06.018

Masoodiyeh, F., Mozdianfard, M. R., Karimi-Sabet, J. Thermodynamic modeling of PVTx properties for several water/hydrocarbon systems in near-critical and supercritical conditions. Korean Journal of Chemical Engineering, 30, 201-212 (2013). https:// doi.org/10.1007/s11814-012-0123-z 
McHugh, M., Krukonis, V. Supercritical fluid extraction: principles and practice, Elsevier (2013).

Mendes, R. L., Nobre, B. P., Coelho, J. P., Palavra, A. F. Solubility of $\beta$-carotene in supercritical carbon dioxide and ethane. The Journal of Supercritical Fluids, 16, 99-106 (1999). https://doi.org/10.1016/ S0896-8446(99)00029-7

Méndez-Santiago, J., Teja, A. S. The solubility of solids in supercritical fluids. Fluid Phase Equilibria, 158, 501-510 (1999). https://doi.org/10.1016/S03783812(99)00154-5

Michelsen, M. L. The isothermal flash problem. Part I. Stability. Fluid Phase Equilibria, 9, 1-19 (1982a). https://doi.org/10.1016/0378-3812(82)85001-2

Michelsen, M. L. The isothermal flash problem. Part II. Phase-split calculation. Fluid Phase Equilibria, 9, 21-40 (1982b). https://doi.org/10.1016/0378$3812(82) 85002-4$

Milovanovic, S., Stamenic, M., Markovic, D., Radetic, M., Zizovic, I. Solubility of thymol in supercritical carbon dioxide and its impregnation on cotton gauze. The Journal of Supercritical Fluids, 84, 173-181 (2013). https://doi.org/10.1016/j. supflu.2013.10.003

Morère, J., Tenorio, M. J., Pando, C., Renuncio, J. A. R., Cabañas, A. Solubility of two metal-organic ruthenium precursors in supercritical $\mathrm{CO}_{2}$ and their application in supercritical fluid technology. The Journal of Chemical Thermodynamics, 58, 55-61 (2013). https://doi.org/10.1016/j.jct.2012.09.029

Mori, T., Miyashita, N., Im, W., Feig, M., Sugita, Y. Molecular dynamics simulations of biological membranes and membrane proteins using enhanced conformational sampling algorithms. Biochimica et Biophysica Acta (BBA)-Biomembranes, 1858, 1635-1651 (2016). https://doi.org/10.1016/j. bbamem.2015.12.032

Nayeem, S. M., Deep, S. Rationalization of poor solubility of TGF- $\beta 3$ using MD simulation. Biochemical and Biophysical Research Communications, 401, 544-547 (2010). https://doi. org/10.1016/j.bbrc.2010.09.090

Nichita, D. V., Petitfrere, M. Phase stability analysis using a reduction method. Fluid Phase Equilibria, 358, 27-39 (2013). https://doi.org/10.1016/j. fluid.2013.08.006

Nielsen, R. P., Valsecchi, R., Strandgaard, M., Maschietti, M. Experimental study on fluid phase equilibria of hydroxyl-terminated perfluoropolyether oligomers and supercritical carbon dioxide. The Journal of Supercritical Fluids, 101, 124-130 (2015). https://doi.org/10.1016/j. supflu.2015.03.011

Noroozi, J., Karimi-Sabet, J., Ghotbi, C., Robert, M. A. Solvation Free Energy and Solubility of acetaminophen and ibuprofen in Supercritical Carbon Dioxide: Impact of the Solvent Model. The
Journal of Supercritical Fluids, 109, 166-176(2016). https://doi.org/10.1016/j.supflu.2015.11.009

Park, C. I., Shin, M. S., Kim, H. Solubility of climbazole and triclocarban in supercritical carbon dioxide: Measurement and correlation. The Journal of Chemical Thermodynamics, 41, 30-34 (2009). https://doi.org/10.1016/j.jct.2008.08.009

Pathak, P., Meziani, M. J., Desai, T., Sun, Y.P. Formation and stabilization of ibuprofen nanoparticles in supercritical fluid processing. The Journal of Supercritical Fluids, 37, 279-286 (2006). https://doi.org/10.1016/j.supflu.2005.09.005

Pauchon, V., Cissé, Z., Chavret, M., Jose, J. A new apparatus for the dynamic determination of solid compoundssolubilityinsupercriticalcarbondioxide: solubility determination of triphenylmethane. The Journal of Supercritical Fluids, 32, 115-121 (2004). https://doi.org/10.1016/j.supflu.2004.03.003

Pereira, L., Santos, P. G. d., Scheer, A. P., Ndiaye, P. M., Corazza, M. L. High pressure phase equilibrium measurements for binary systems $\mathrm{CO}_{2}+1$-pentanol and $\mathrm{CO}_{2}+1$-hexanol. The Journal of Supercritical Fluids, 88, 38-45 (2014). https://doi.org/10.1016/j. supflu.2014.01.005

Rahman, I., Das, A. K., Mankar, R. B., Kulkarni, B. Evaluation of repulsive particle swarm method for phase equilibrium and phase stability problems. Fluid Phase Equilibria, 282, 65-67 (2009). https:// doi.org/10.1016/j.fluid.2009.04.014

Rajaei, H., Hezave, A. Z., Lashkarbolooki, M., Esmaeilzadeh, F. Representing experimental solubility of phenylephrine hydrochloride in supercritical carbon dioxide and modeling solute solubility using semiempirical correlations. The Journal of Supercritical Fluids, 75, 181-186 (2013). https://doi.org/10.1016/j.supflu.2012.11.014

Rebelatto, E. A., Bender, J. P., Corazza, M. L., Ferreira, S. R., Oliveira, J. V., Lanza, M. High-pressure phase equilibrium data for the (carbon dioxide+ 1-lactide+ethanol) system. The Journal of Chemical Thermodynamics, 86, 37-42 (2015). https://doi. org/10.1016/j.jct.2015.02.005

Reddy, S. N., Madras, G. Solubilities of benzene derivatives in supercritical carbon dioxide. Journal of Chemical \& Engineering Data, 56, 1695-1699 (2011). https://doi.org/10.1021/je100863p

Reverchon, E., Adami, R., Cardea, S., Della Porta, G. Supercritical fluids processing of polymers for pharmaceutical and medical applications. The Journal of Supercritical Fluids, 47, 484-492 (2009). https://doi.org/10.1016/j.supflu.2008.10.001

Ruttarattanamongkol, K., Wagner, M. E., Rizvi, S. S. Properties of yeast free bread produced by supercritical fluid extrusion (SCFX) and vacuum baking. Innovative Food Science \& Emerging Technologies, 12, 542-550 (2011). https://doi. org/10.1016/j.ifset.2011.07.006 
Sabegh, M. A., Rajaei, H., Esmaeilzadeh, F., Lashkarbolooki, M. Solubility of ketoprofen in supercritical carbon dioxide. The Journal of Supercritical Fluids, 72, 191-197 (2012). https:// doi.org/10.1016/j.supflu.2012.08.008

Karimi-Sabet, J., Jafarinejad, S., Golzary, A. Supercritical water oxidation for the recovery of dysprosium ion from aqueous solutions. Int. Res. J. Appl. Basic. Sci, 8, 1079-1083 (2014).

Karimi-Sabet, J., Ghotbi, C., Dorkoosh, F. Application of response surface methodology for optimization of paracetamol particles formation by RESS method. Journal of Nanomaterials, 43 (2012). https://doi.org/10.1155/2012/340379

Karimi-Sabet, J., Ghotbi, C., Dorkoosh, F., Striolo, A. Solubilities of acetaminophen in supercritical carbon dioxide with and without menthol cosolvent: Measurement and correlation. Scientia Iranica, 19, 619-625 (2012). https://doi.org/10.1016/j. scient.2011.11.046

Perrut, M. Sterilization and virus inactivation by supercritical fluids (a review). Journal of Supercritical Fluids, 66, 359-371 (2012). https:// doi.org/10.1016/j.supflu.2011.07.007

Sadus, R. J. High pressure phase behaviour of multicomponent fluid mixtures, Elsevier (2012).

Santos, P. dos, Zabot, G. L., Meireles, M. A.A., Mazutti, M. A., Martínez, J. Synthesis of eugenyl acetate by enzymatic reactions in supercritical carbon dioxide. Biochemical Engineering Journal, 114, 1-9 (2016). https://doi.org/10.1016/j.bej.2016.06.018

Schultz, A. J., Shaul, K. R., Yang, S., Kofke, D. A. Modeling solubility in supercritical fluids via the virial equation of state. The Journal of Supercritical Fluids, 55, 479-484 (2010). https:// doi.org/10.1016/j.supflu.2010.10.042

Seo, W.-G., Zhou, D., Tsukihashi, F. Calculation of thermodynamic properties and phase diagrams for the $\mathrm{CaO}-\mathrm{CaF}_{2}, \mathrm{BaO}-\mathrm{CaO}$ and $\mathrm{BaO}-\mathrm{CaF}_{2}$ systems by molecular dynamics simulation. Materials Transactions, 46, 643-650 (2005). https://doi. org/10.2320/matertrans.46.643

Shamsipur, M., Fasihi, J., Khanchi, A., Yamini, Y., Valinezhad, A., Sharghi, H. Solubilities of some 9, 10-anthraquinone derivatives in supercritical carbon dioxide: A cubic equation of state correlation. The Journal of Supercritical Fluids, 47, 154-160 (2008). https://doi.org/10.1016/j.supflu.2008.07.002

Shamsipur, M., Fathi, M. R., Yamini, Y., Ghiasvand, A. R. Solubility determination of nitrophenol derivatives in supercritical carbon dioxide. The Journal of Supercritical Fluids, 23, 225-231 (2002). https:/doi.org/10.1016/S0896-8446(01)00143-7

Shariati, A., Peters, C. J. Recent developments in particle design using supercritical fluids. Current Opinion in Solid State and Materials Science,
7, 371-383 (2003). https://doi.org/10.1016/j. cossms.2003.12.001

Shen, Z., Wang, H., Li, G. Numerical simulation of the cutting-carrying ability of supercritical carbon dioxide drilling at horizontal section. Petrol Explor Dev, 38, 233-236 (2011). https://doi.org/10.1016/ S1876-3804(11)60028-1

Shimoyama, Y., Iwai, Y.,Abeta, T.,Arai, Y. Measurement and correlation of vapor-liquid equilibria for ethanol+ethyl laurate and ethanol+ethyl myristate systems near critical temperature of ethanol. Fluid Phase Equilibria, 264, 228-234 (2008). https://doi. org/10.1016/j.fluid.2007.11.014

Shojaee, S. A., Rajaei, H., Hezave, A. Z., Lashkarbolooki, M., Esmaeilzadeh, F. Experimental investigation and modeling of the solubility of carvedilol in supercritical carbon dioxide. The Journal of Supercritical Fluids, 81, 42-47 (2013). https://doi.org/10.1016/j.supflu.2013.04.013

Skarmoutsos, I., Kampanakis, L. I., Samios, J. Investigation of the vapor-liquid equilibrium and supercritical phase of pure methane via computer simulations. Journal of Molecular Liquids, 117, 33-41 (2005). https://doi.org/10.1016/j. molliq.2004.08.014

Sofronova, A. A., Evstafyeva, D. B., Izumrudov, V. A., Muronetz, V. I., Semenyuk, P. I. Proteinpolyelectrolyte complexes: Molecular dynamics simulations and experimental study. Polymer, 113, 39-45 (2017). https://doi.org/10.1016/j. polymer.2017.02.047

Sousa, H. C. de, Costa, M. S., Coimbra, P., Matias, A. A., Duarte, C. M. Experimental determination and correlation of meloxicam sodium salt solubility in supercritical carbon dioxide. The Journal of Supercritical Fluids, 63, 40-45 (2012). https://doi. org/10.1016/j.supflu.2011.12.004

Sparks, D. L., Hernandez, R., Estévez, L. A. Evaluation of density-based models for the solubility of solids in supercritical carbon dioxide and formulation of a new model. Chemical Engineering Science, 63, 4292-4301 (2008). https://doi.org/10.1016/j. ces.2008.05.031

Speybrouck, D., Lipka, E. Preparative supercritical fluid chromatography: A powerful tool for chiral separations. Journal of Chromatography A, 1467, 33-55 (2016). https://doi.org/10.1016/j. chroma.2016.07.050

Staudt, P., Cardozo, N., Soares, R. D. P. Phase stability analysis using a modified affine arithmetic. Computers \& Chemical Engineering, 53, 190-200 (2013). https://doi.org/10.1016/j. compchemeng.2013.03.011

Stevens, R., Roermund, J. van, Jager, M., Loos, T. W. de, Arons, J. de S. High-pressure vapourliquid equilibria in the systems carbon dioxide+2- 
butanol+2-butyl acetate+ vinyl acetate and calculations with three EOS methods. Fluid Phase Equilibria, 138, 159-178 (1997). https://doi. org/10.1016/S0378-3812(97)00163-5

Streett, W. B. Phase behavior in fluid and solid mixtures at high pressures. Pure and Applied Chemistry, 61, 143-152 (1989). https://doi.org/10.1351/ pac198961020143

Stubbs, J. M. Monte Carlo simulation of solute extraction via supercritical carbon dioxide from poly (ethylene glycol). Fluid Phase Equilibria, 305, 76-82 (2011). https://doi.org/10.1016/j.fluid.2011.03.014

Su, C.-S., Chen, Y.-M., Chen, Y.-P. Correlation of solid solubilities for phenolic compounds and steroids in supercritical carbon dioxide using the solution model. Journal of the Taiwan Institute of Chemical Engineers, 42, 608-615 (2011). https:// doi.org/10.1016/j.jtice.2010.11.005

Su, C.-S., Chen, Y.-P. Correlation for the solubilities of pharmaceutical compounds in supercritical carbon dioxide. Fluid Phase Equilibria, 254, 167-173 (2007). https://doi.org/10.1016/j.fluid.2007.03.004

Sung, H.-D., Shim, J.-J. Solubility of CI disperse red 60 and CI disperse blue 60 in supercritical carbon dioxide. Journal of Chemical \& Engineering Data, 44, 985-989 (1999). https://doi.org/10.1021/ je990018t

Suzuki, T., Tsuge, N., Nagahama, K. Solubilities of ethanol, 1-propanol, 2-propanol and 1-butanol in supercritical carbon dioxide at $313 \mathrm{~K}$ and $333 \mathrm{~K}$. Fluid Phase Equilibria, 67, 213-226 (1991). https:// doi.org/10.1016/0378-3812(91)90057-E

Tabernero, A., Valle, E. M. M. del, Galán, M. Á. A comparison between semiempirical equations to predict the solubility of pharmaceutical compounds in supercritical carbon dioxide. The Journal of Supercritical Fluids, 52, 161-174 (2010). https:// doi.org/10.1016/j.supflu.2010.01.009

Takeshita, Y., Sato, Y. Measurement of copper compound solubility in supercritical carbon dioxide and correlation using a solution model. The Journal of Supercritical Fluids, 24, 91-101 (2002). https:// doi.org/10.1016/S0896-8446(02)00004-9

Tamura, K., Alwi, R. S. Solubility of anthraquinone derivatives in supercritical carbon dioxide. Dyes and Pigments, 113, 351-356 (2015). https://doi. org/10.1016/j.dyepig.2014.09.003

Tamura, K., Alwi, R. S., Tanaka, T., Shimizu, K. Solubility of 1-aminoanthraquinone and 1-nitroanthraquinone in supercritical carbon dioxide. The Journal of Chemical Thermodynamics, 104, 162-168 (2017). https://doi.org/10.1016/j. jct.2016.09.032

Tang, Z., Jin, J.-S., Yu, X.-Y., Zhang, Z.-T., Liu, H.-T. Equilibrium solubility of pure and mixed 3,5-dinitrobenzoic acid and 3-nitrobenzoic acid in supercritical carbon dioxide. Thermochimica Acta, 517, 105-114 (2011). https://doi.org/10.1016/j. tca.2011.01.039

Tang, Z., Jin, J.-S., Zhang, Z.-T., Liu, H.-T. New experimental data and modeling of the solubility of compounds in supercritical carbon dioxide. Industrial \& Engineering Chemistry Research, 51, 5515-5526 (2012). https://doi.org/10.1021/ ie 2016224

Tenorio, M. J., Cabañas, A., Pando, C., Renuncio, J. A. R. Solubility of $\mathrm{Pd}(\mathrm{hfac})$, and $\mathrm{Ni}(\mathrm{hfac}) \cdot 2 \mathrm{H}_{2} \mathrm{O}$ in supercritical carbon dioxide pure and modified with ethanol. The Journal of Supercritical Fluids, 70, 106-111 (2012). https://doi.org/10.1016/j. supflu.2012.06.014

Tomberli, B., Goldman, S., Gray, C., Saldaña, M., Temelli, F. Using solute structure to predict solubility of organic molecules in supercritical carbon dioxide. The Journal of Supercritical Fluids, 37, 333-341 (2006). https://doi.org/10.1016/j. supflu.2005.10.008

Tsuji, T., Tanaka, S., Hiaki, T., Saito, R. Measurements of bubble point pressure for $\mathrm{CO}_{2}+$ decane and $\mathrm{CO}_{2}+$ lubricating oil. Fluid Phase Equilibria, 219, 87-92 (2004). https://doi.org/10.1016/j.fluid.2004.01.019

Valderrama, J. O., Alvarez, V. H. Temperature independent mixing rules to correlate the solubility of solids in supercritical carbon dioxide. The Journal of Supercritical Fluids, 32, 37-46 (2004). https://doi.org/10.1016/j.supflu.2003.12.016

van Konynenburg, P., Scott, R. Critical lines and phase equilibria in binary Van der Waals mixtures. Philosophical Transactions of the Royal Society of London A: Mathematical, Physical and Engineering Sciences, 298, 495-540 (1980). https:// doi.org/10.1098/rsta.1980.0266

van Konynenburg, P. H. Critical lines and phase equilibria in binary mixtures, University of California, Los Angeles (1968).

Wang, Z., Kern, J. L., Laird, B. B. The phase equilibrium, transport and local liquid structure of the methanol/water/ethylene ternary system: A molecular simulation study. Fluid Phase Equilibria, 429, 275-280 (2016). https://doi.org/10.1016/j. fluid.2016.09.001

Wu, H., Zhu, J., Wang, Y., Chang, C., Jin, J. Measurement and modeling for solubility of 3-hydroxybenzaldehyde and its mixture with 4-hydroxybenzaldehyde in supercritical carbon dioxide. Fluid Phase Equilibria, 409, 271-279 (2016). https://doi.org/10.1016/j.fluid.2015.10.012

Xing, H., Yang, Y., Su, B., Huang, M., Ren, Q. Solubility of artemisinin in supercritical carbon dioxide. Journal of Chemical \& Engineering Data, 48, 330-332 (2003). https://doi.org/10.1021/ je0255751 
Yang, D., Hou, M., Ning, H., Liu, Y., Han, B. Highpressure phase behaviors of $\mathrm{CO}_{2}+1$-propanol+ionic liquid ternary systems. The Journal of Supercritical Fluids, 69, 108-112 (2012). https://doi. $\operatorname{org} / 10.1016 /$ j.supflu.2012.05.015

Yang, H., Zhong, C. Modeling of the solubility of aromatic compounds in supercritical carbon dioxide-cosolvent systems using SAFT equation of state. The Journal of Supercritical Fluids, 33, 99-106 (2005). https://doi.org/10.1016/j. supflu.2004.05.008

Yazdizadeh, M., Eslamimanesh, A., Esmaeilzadeh, F. Thermodynamic modeling of solubilities of various solid compounds in supercritical carbon dioxide: Effects of equations of state and mixing rules. The Journal of Supercritical Fluids, 55, 861-875 (2011). https://doi.org/10.1016/j.supflu.2010.10.019

Yazdizadeh, M., Eslamimanesh, A., Esmaeilzadeh, F. Applications of cubic equations of state for determination of the solubilities of industrial solid compounds in supercritical carbon dioxide: A comparative study. Chemical Engineering Science, 71, 283-299 (2012). https://doi.org/10.1016/j. ces.2011.10.055

Yeo, S.-D., Kiran, E. Formation of polymer particles with supercritical fluids: a review. The Journal of Supercritical Fluids, 34, 287-308 (2005). https:// doi.org/10.1016/j.supflu.2004.10.006

Yoda, S., Mizuno, Y., Furuya, T., Takebayashi, Y., Otake, K., Tsuji, T., Hiaki, T. Solubility measurements of noble metal acetylacetonates in supercritical carbon dioxide by high performance liquid chromatography (HPLC). The Journal of Supercritical Fluids, 44, 139-147 (2008). https:// doi.org/10.1016/j.supflu.2007.11.002

Yu, Z.-R., Rizvi, S. S., Zollweg, J. A. Phase equilibria of oleic acid, methyl oleate, and anhydrous milk fat in supercritical carbon dioxide. The Journal of Supercritical Fluids, 5, 114-122 (1992). https://doi. org/10.1016/0896-8446(92)90028-I

Yu, Z.-R., Singh, B., Rizvi, S. S., Zollweg, J. A. Solubilities of fatty acids, fatty acid esters, triglycerides, and fats and oils in supercritical carbon dioxide. The Journal of Supercritical Fluids, 7, 51-59 (1994). https://doi.org/10.1016/08968446(94)90006-X

Yuan, H., Gosling, C., Kokayeff, P., Murad, S. Prediction of hydrogen solubility in heavy hydrocarbons over a range of temperatures and pressures using molecular dynamics simulations. Fluid Phase Equilibria, 299, 94-101 (2010). https:// doi.org/10.1016/j.fluid.2010.09.010

Zaherzadeh, A., Karimi-Sabet, J., Mousavian, S. M. A., Ghorbanian, S. Optimization of flat sheet hydrophobic membranes synthesis via supercritical $\mathrm{CO}_{2}$ induced phase inversion for direct contact membrane distillation by using response surface methodology (RSM). The Journal of Supercritical Fluids, 103, 105-114 (2015). https://doi. org/10.1016/j.supflu.2015.04.030

Zeng, Y., Li, H., Moghadam, P. Z., Xu, Y., Hu, J., $\mathrm{Ju}, \mathrm{S}$. Monte Carlo simulations of phase behavior and microscopic structure for supercritical $\mathrm{CO}_{2}$ and thiophene mixtures. The Journal of Supercritical Fluids, 95, 214-221 (2014). https:// doi.org/10.1016/j.supflu.2014.08.028

Zhang, P., Yang, H.-J., Xu, L. Solubility and partial molar volume of $\mathrm{N}, \mathrm{N}$-dimethylformamide diethyl acetal in supercritical carbon dioxide: Measurement and correlations. Journal of Industrial and Engineering Chemistry, 20, 1243-1246 (2014). https://doi.org/10.1016/j.jiec.2013.09.025

Zhu, J., Chang, C., Wu, H., Jin, J. Solubility of polyvinyl alcohol in supercritical carbon dioxide and subcritical 1,1,1,2-tetrafluoroethane. Fluid Phase Equilibria, 404, 61-69 (2015). https://doi. org/10.1016/j.fluid.2015.06.031

Zhu, Y., Wen, H., Xu, Z. Global stability analysis and phase equilibrium calculations at high pressures using the enhanced simulated annealing algorithm. Chemical Engineering Science, 55, 3451-3459 (2000). https://doi.org/10.1016/S00092509(00)00015-4 